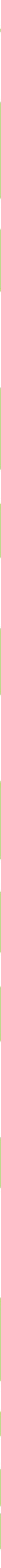


A Portada: Edificio Miguel de Mendoza \#14, CDMX México (2015) Arquitectos: PDI Diseño + construcción Fotografía: Mtro. Rodrigo García Cué (Fotógrafo) 2017 Teléfono: $+(52) 0457773359173$ rodrigogcue@gmail.com - www.rodrigogcue.com (c) (i) \$
A Orientación editorial

\section{Enfoque y alcance}

La Revista de Arquitectura (ISSN 1657-0308 Impresa y E-ISSN 2357-626X en línea) es una publicación seriada de acceso abierto, arbitrada mediante revisión por pares (doble ciego) e indexada, en donde se publican resultados de investigación originales e inéditos.

Está dirigida a la comunidad académica y profesional de las áreas afines a la disciplina. Es editada por la Facultad de Diseño y el Centro de Investigaciones (CIFAR) de la Universidad Católica de Colombia en Bogotá (Colombia).

La principal área científica a la que se adscribe la Revista de Arquitectura según la OCDE es:

Gran área: 6. Humanidades

Área: 6.D. Arte

Disciplina: 6D07. Arquitectura y Urbanismo

También se publican artículos de las disciplinas como 2A02, Ingeniería arquitectónica; 5G03, Estudios urbanos (planificación y desarrollo); 6D07, Diseño.

Los objetivos de la Revista de Arquitectura son:

- Promover la divulgación y difusión del conocimiento generado a nivel local, nacional e internacional

- Conformar un espacio para la construcción de comunidades académicas y la discusión en torno a las secciones definidas.

- Fomentar la diversidad institucional y geográfica de los autores que participan en la publicación.

- Potenciar la discusión de experiencias e intercambios científicos entre investigadores y profesionales.

- Contribuir a la visión integral de la arquitectura, por medio de la concurrencia y articulación de las secciones mediante la publicación de artículos de calidad.

- Publicar artículos originales e inéditos que han pasado por revisión de pares, para asegurar que se cumplen las normas éticas, de calidad, validez científica, editorial e investigativa.

- Fomentar la divulgación de las investigaciones y actividades desarrolladas en la Universidad Católica de Colombia.
Palabras clave de la Revista de Arquitectura: arquitectura, diseño, educación arquitectónica, proyecto y construcción, urbanismo.

Idiomas de publicación: español, inglés, portugués y francés.

Título abreviado: Rev. Arquit.

Titulo corto: RevArq

\section{Políticas de sección}

La revista se estructura en tres secciones correspondientes a las líneas de investigación activas y aprobadas por la institución, y dos complementarias, que presentan dinámicas propias de la Facultad de Diseño y las publicaciones relacionadas con la disciplina.

Cultura y espacio urbano. En esta sección se publican los artículos que se refieren a fenómenos sociales en relación con el espacio urbano, atendiendo aspectos de la historia, el patrimonio cultural y físico, y la estructura formal de las ciudades y el territorio.

Proyecto arquitectónico y urbano. En esta sección se presentan artículos sobre el concepto de proyecto, entendido como elemento que define y orienta las condiciones proyectuales que devienen en los hechos arquitectónicos o urbanos, y la forma como estos se convierten en un proceso de investigación y nuevo de conocimiento. También se presentan proyectos que sean resultados de investigación, los cuales se validan por medio de la ejecución y transformación en obra construida del proceso investigativo. También se contempla la publicación de investigaciones relacionadas con la pedagogía y didáctica de la arquitectura, el urbanismo y el diseño.

Tecnología, medioambiente y sostenibilidad. En esta sección se presentan artículos acerca de sistemas estructurales, materiales y procesos constructivos, medioambiente y gestión, relacionados con los entornos social-cultural, ecológico y económico.

Desde la Facultad. En esta sección se publican artículos generados en la Facultad de Diseño, relacionados con las actividades de docencia, extensión, formación en investigación o internacionalización, las cuales son reflejo de la dinámica y de las actividades realizadas por docentes, estudiantes y egresados; esta sección no puede superar el $20 \%$ del contenido.

Textos. En esta sección se publican reseñas, traducciones y memorias de eventos relacionados con las publicaciones en Arquitectura y Urbanismo.
Desde 1999 y hasta el 2015, la Revista de Arquitectura publicó un volumen al año, a partir del 2016 se publicarán dos números por año en periodo anticipado, enero-junio y julio-diciembre, pero también maneja la publicación anticipada en línea de los artículos aceptados (versión Post-print del autor).

La Revista de Arquitectura se divulga mediante versiones digitales (PDF, HTML, EPUB, XML) e impresas con un tiraje de 700 ejemplares, los tiempos de

Universidad Católica de Colombia (2017, enero-junio).

Revista de Arquitectura, $19(\mathrm{I})$,

I-96. Doi: 10.14718

ISSN: 1657-0308

E-ISSN: 2357-626X

Especificaciones:

Formato: $34 \times 24 \mathrm{~cm}$

Papel: Mate $115 \mathrm{~g}$

Tintas: Negro y policromía producción de estas versiones dependerán de los cronogramas establecidos por la editorial.

Los tiempos de recepción-revisión-aceptación pueden tardar entre seis y doce meses dependiendo del flujo editorial de cada sección y del proceso de revisión y edición adelantado.

Con el usuario y contraseña asignados, los autores pueden ingresar a la plataforma de gestión editorial y verificar el estado de revisión, edición o publicación del artículo.
A Canje

La Revista de Arquitectura está interesada en establecer canje con publicaciones académicas, profesionales o científicas del área de Arquitectura y Urbanismo, como medio de reconocimiento y discusión de la producción científica en el campo de acción de la publicación.

\section{Mecanismo}

Para establecer canje por favor descargar, diligenciar y enviar el formato: RevArq FP20 Canjes

\section{Contacto}

Dirección postal:

Avenida Caracas No. 46-72.

Universidad Católica de Colombia

Bogotá D.C.(Colombia)

Código postal: 111311

Facultad de Diseño

Centro de Investigaciones (CIFAR).

Sede El Claustro. Bloque "L", 4 piso

Diag. 46a No. $15 \mathrm{~b}-10$

Editor, Arq. César Andrés Eligio Triana

Teléfonos:

+57 (1) $3277300-3277333$

Ext. 3109; 3112 o 5146

Fax: +57 (1) 2858895
Correo electrónico:

revistadearquitectura@ucatolica.edu.co cifar@ucatolica.edu.co

Página WEB:

www.ucatolica.edu.co

vínculo Revistas científicas

http://publicaciones.ucatolica.edu.co/ revistas-cientificas

http://editorial.ucatolica.edu.co/ojsucatolica/ revistas_ucatolica/index.php/RevArq 
Universidad Católica de Colombia

Presidente

Édgar Gómez Betancourt

Vicepresidente - Rector

Francisco José Gómez Ortiz

Vicerrector Jurídico

Edwin de Jesús Horta Vásquez

Vicerrector Administrativo

Édgar Gómez Ortiz

Decano Académico

Elvers Medellín Lozano

Directora de Investigaciones

Elisa Urbina Sánchez

Directora Editorial

Stella Valbuena García
Facultad de Diseño

Decano

Werner Gómez Benítez

Director de docencia

Jorge Gutiérrez Martínez

Directora de extensión

Adriana Pedraza Pacheco

Director de investigación

Hernando Verdugo Reyes

Director de gestión de calidad

Augusto Forero La Rotta

Comité asesor externo

Facultad de Diseño

Alberto Miani Uribe

Giovanni Ferroni Del Valle

Samuel Ricardo Vélez

Lorenzo Castro
Facultad de Diseño

Centro de Investigaciones - CIFAR

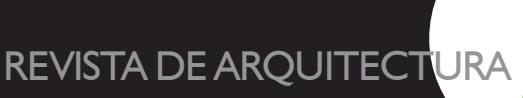

, tectura

Revista de acceso abierto, arbitrada e indexada

Publindex Categoría B. Índice Bibliográfico Nacional IBN. Colombia.

Esci. Emerging Source Citation Index

Doaj. Directory of Open Access Journ

Ebsco. EBSCOhost Research Databases. Estados Unidos.

Proquest. ProQuest Research LibraryProQuest Research

Library ProQuest Research Library. Estados Unidos

Redalyc. Red de Revistas Científicas de América Latina

y el Caribe, España y Portugal. Sistema de Información

Científica. México.

Redib. Red Iberoamericana de Innovación y Conocimiento Científico. España

Latindex. Sistema Regional de Información en Línea para Revistas Científicas de América Latina, el Caribe, España y Portugal (Directorio y catálogo). México.

Clase. Base de datos bibliográfica de revistas de ciencias sociales y humanidades. Universidad Autónoma México. Dialnet. Fundación Dialnet - Biblioteca de la Universidad de La Rioja. España.

Actualidad Iberoamericana. (Índice de Revistas) Centro de Información Tecnológica (CIT). Chile.

Arla. Asociación de revistas latinoamericanas de arquitectura.

Editorial

Av. Caracas N 46-72, piso 5

@ucatolica.edu.co

whw.ucatolica.edu.co

Impresión:

JAVEGRAF

Calle 46A N $82-54$ Int. 2

Bogotá, D. C., Colombia

http://www.javegraf.com.co/index.php

Junio de 2017
Revista de Arquitectura

Director

Werner Gómez Benítez

Editor

César Eligio-Triana

Editores de sección

(4) Myriam Stella Díaz Osorio

(4) Carolina Rodríguez Ahumada

(4) Anna Maria Cereghino Fedrigo

Consejo editorial

Werner Gómez Benítez

Jorge Gutiérrez Martínez

César Eligio-Triana

Hernando Verdugo Reyes

\section{Equipo editorial}

Coordinadora editorial

María Paula Godoy Casasbuenas mpgodoy@ucatolica.edu.co

Diseño y montaje

Juanita Isaza

juanaisaza@gmail.com

Traductoras

Inglés

Erika Tanacs

etanacs25@gmail.com

Portugués

Roanita Dalpiaz

roanitad@gmail.com

Correctora de estilo

María José Díaz Granados M.

mariajose_dgm@yahoo.com.co

Página Web

Centro de investigaciones (CIFAR)

Distribución y canjes

Claudia Álvarez Duquino

calvarez@ucatolica.edu.co
Comité editorial y científico

Cultura y espacio urbano

Carlos Mario Yory, PhD

Universidad Católica de Colombia. Bogotá, Colombia

Sonia Berjman, $\mathrm{PhD}$

ICOMOS-IFLA, Buenos Aires, Argentina

Juan Carlos Pérgolis, MSc Universidad Piloto de Colombia. Bogotá, Colombia

Beatriz García Moreno, PhD

Universidad Nacional de Colombia. Bogotá, Colombia

Proyecto arquitectónico y urbano

Jean-Philippe Garric, PhD, HDR

Université Paris I Panthéon-Sorbonne. Paris, Francia

Debora Domingo Calabuig, PhD

Universidad Politécnica de Valencia, España

Hugo Mondragón López, PhD

Pontificia Universidad Católica de Chile. Santiago, Chile

Juan Pablo Duque Cañas, PhD

Universidad Nacional de Colombia. Bogotá, Colombia

Jorge Grané del Castillo, Msc

Universidad de Costa Rica. San José, Costa Rica

Tecnología, medioambiente y sostenibilidad

Mariano Vázquez Espí, PhD.

Universidad Politéenica de Madrid, España.

Luis Carlos Herrera Sosa, PhD

Universidad Autónoma de Ciudad Juárez, México

Claudio Varini, PhD

Universidad Católica de Colombia. Bogotá, Colombia

Luis Gabriel Gómez Azpeitia, PhD

Universidad de Colima. Colima, México 

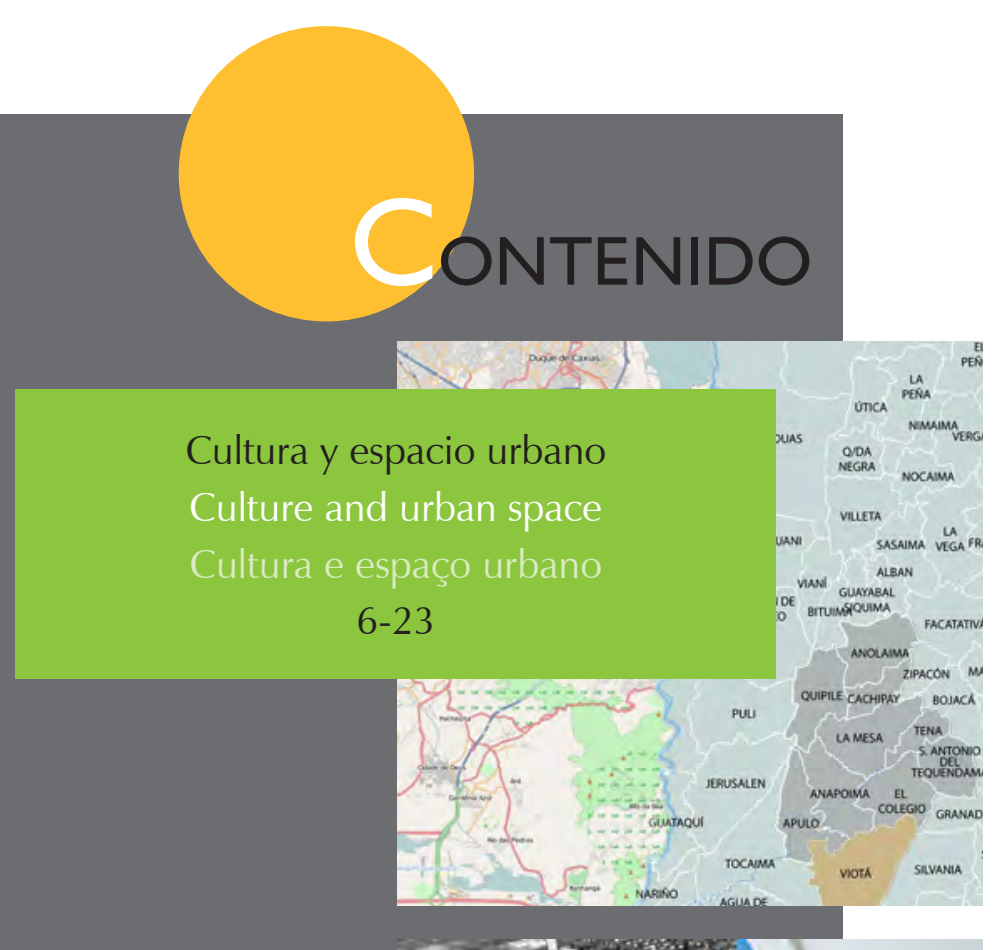

Proyecto arquitectónico y urbano

Architectural and urban project

Projeto arquitetônico e urbano

$$
\text { 24-41 }
$$

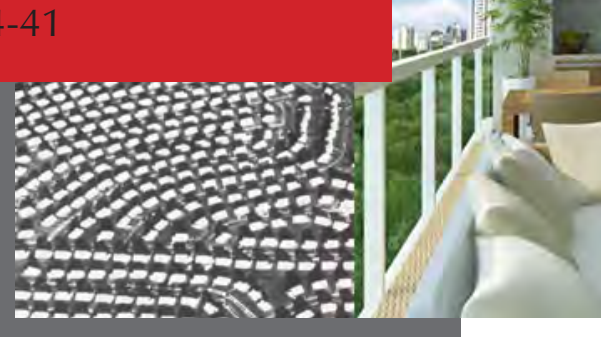

.

Tecnología, medioambiente y sostenibilidad

Technology, environment and sustainability Tecnologia, meio ambiente e sustentabilidade 42-69
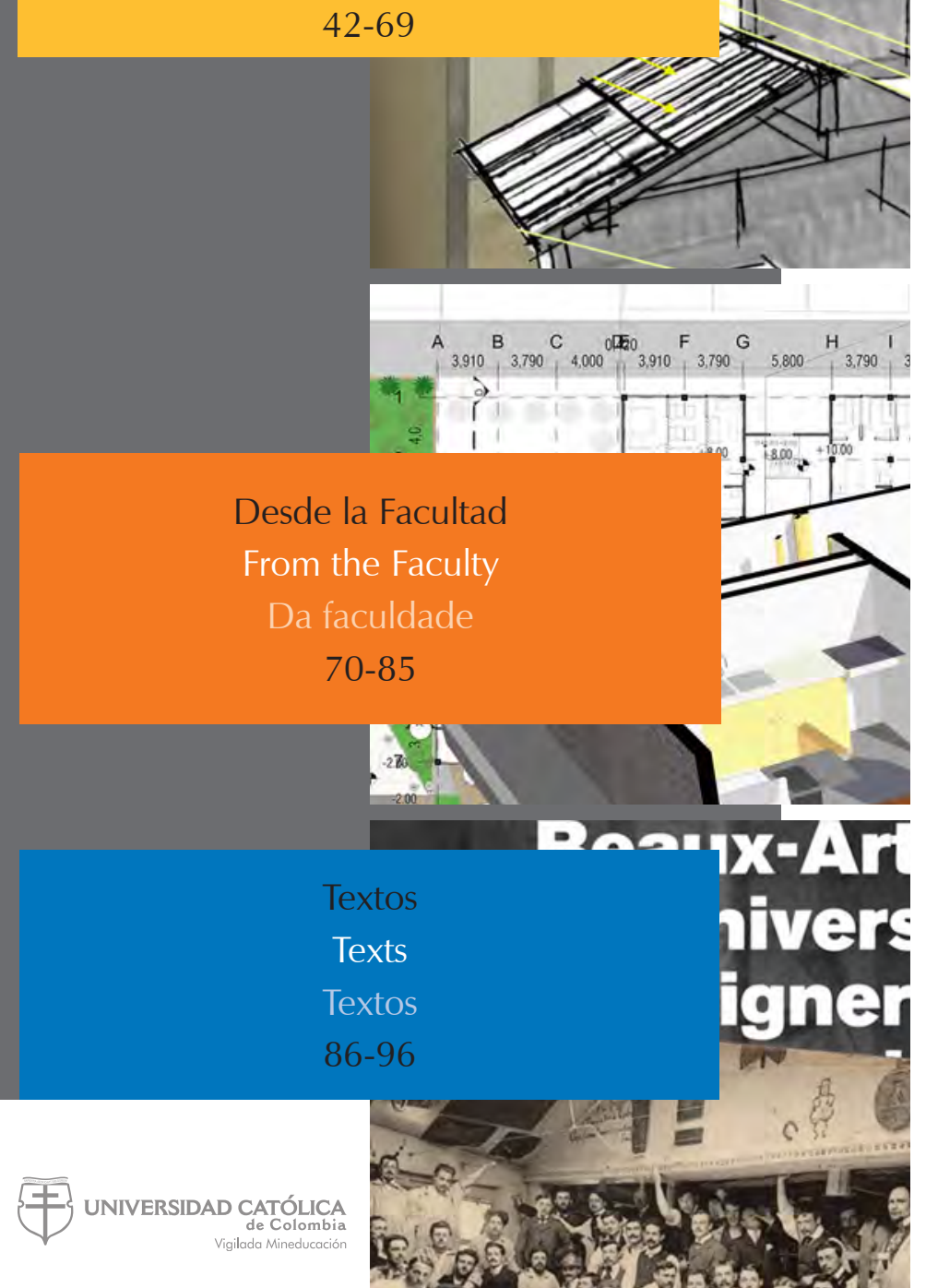

\section{A favela é um cenário:}

tematização e cenarização nas favelas cariocas

Sergio-Moraes-Rego Fagerlande

Pág. 6

Gestión cultural del patrimonio en Viotá,

\section{Cundinamarca}

Diana María Blanco-Ramírez

Pág. 14

De la utopía a la distopía doméstica

La creación de la vivienda modelo norteamericana

Carlos Santamarina-Macho

Pág. 24

La varanda gourmet brasileña:

arquitectura hedonista y distinción social

Bruno Cruz-Petit

Alejandro Pérez-Duarte Fernández

Pág. 33

Techo plantado como dispositivo de

climatización pasiva en el trópico

Iván Osuna-Motta

Carlos Herrera-Cáceres

Oswaldo López-Bernal

Pág. 42

Criterios de integración de energía solar activa en arquitectura

Potencial tecnológico y consideraciones proyectuales

Esteban Zalamea-León

Felipe Quesada

Pág. 56

Prototipos flexibles

Proyecto habitacional en el barrio popular

Buenos Aires (Soacha)

Mildred Paola Laiton-Suárez

Pág. 70

La pedagogía del taller en la enseñanza de la arquitectura

Una aproximación cultural y material al caso francés (siglos XIX y XX)

Guy Lambert

Traductores:

Andrés Ávila-Gómez

Diana Carolina Ruiz

Pág. 86 


\title{
Techo plantado como dispositivo de climatización pasiva en el trópico
}

\author{
Iván Osuna-Motta \\ Pontificia Universidad Javeriana, Cali (Colombia) \\ Facultad de Humanidades y Ciencias Sociales \\ Carrera de Arquitectura \\ Carlos Herrera-Cáceres, Oswaldo López-Bernal \\ Universidad del Valle, Cali (Colombia) \\ Grupo Hábitat y Desarrollo Sostenible
}

Osuna-Motta, I., Herrera-Cáceres, C., \& López-Bernal, 0. (2017). Techo plantado como dispositivo de climatización pasiva en el trópico Revista de Arquitectura, 19(I), 42-55. doi: http://dx.doi.org/10.14718/ RevArg. 2017.19.1.11109

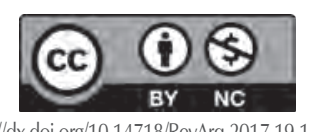

Iván Osuna-Motta

Arquitecto, Universidad de los Andes, Bogotá (Colombia).

Magíster en Arquitectura y Urbanismo, Universidad del Valle, Cali (Colombia).

Director de la carrera de Arquitectura, Pontificia Universidad Javeriana, Cali (Colombia).

Profesor del pregrado de Arquitectura, Pontificia Universidad Javeriana, Cali, y de la Maestría en Arquitectura y Urbanismo, Universidad del Valle.

Lead Faculty Advisor del equipo Calicivita, ganador del segundo puesto en el Solar Decathlon Latin America \& Caribbean 2015 .

(D) http://orcid.org/0000-000I-5137-2603

ivan.osuna@javerianacali.edu.co

Carlos Herrera-Cáceres

Ingeniero mecánico, Universidad del Valle, Cali (Colombia).

PhD Lehigh University: Bethlehem, PA, United States.

Profesor titular, Escuela Ingeniería Mecá $\neg$ nica y Escuela de arquitectura, Universidad del Valle, Facultad de Ingeniería, Cali (Colombia).

Enfasis en ventilación y climatización pasiva y mecánica, iluminación natural, transferencia de energía en edificaciones, control de infecciones aéreas por medios pasivos y mecánicos en hospitales, eficiencia energética y sostenibilidad.

(1) http://orcid.org/0000-0003-3983-2800

carlos.herrera@correounivalle.edu.co

Oswaldo López-Bernal

Arquitecto, Universidad Católica de Colombia, Bogotá (Colombia).

Magíster en Gestión Ambiental Urbana, Universidad Javeriana.

Doctor en Urbanismo, Universidad Nacional Autónoma de México.

Estancia posdoctoral en la Universidad de Montreal como parte del programa de Faculty Research Program del Gobierno canadiense.

Profesor e investigador de la Escuela de Arquitectura, Universidad del Valle, Cali (Colombia).

(i) http://orcid.org/0000-0003-378I-2582

oswaldo.lopez@correounivalle.edu.co

Resumen

Se determina el comportamiento térmico de un prototipo experimental de techo plantado, que pueda ser instalado sobre sistemas de cubiertas inclinadas en láminas onduladas de fibrocemento, ampliamente utilizas en nuestro medio. La investigación demostró las ventajas del uso de los techos plantados como dispositivos de enfriamiento pasivo, en las condiciones climáticas y meteorológicas específicas de la ciudad de Cali, donde la cubierta representa la mayor fuente de ganancia térmica. Durante la fase experimental, se construyeron un módulo testigo y dos módulos de prueba sobre los cuales se instalaron los prototipos y se registraron periódicamente los valores de temperatura superficial de la envolvente, y de temperatura y humedad relativa del aire exterior e interior. Utilizando un método comparativo, se pudo establecer y cuantificar el efecto positivo del prototipo sobre el comportamiento térmico de la envolvente en las condiciones locales, demostrando su utilidad.

Palabras clave: confort térmico, enfriamiento pasivo, sostenibilidad, transferencia de calor, techos verdes.

\section{Green roofs as a passive cooling device in the tropics}

Abstract

The study aims to determine the thermal performance of an experimental green-roof prototype that can be installed on pitched roofs of fiber cement corrugated sheets, widely used in our environment. Research results showed the advantages of using green roofs as a passive cooling device in the specific climate and weather conditions of a place such as Cali, Colombia, where roofs are the greatest source of heat gain. During the experimental phase, a control module and two test modules were built, where the green-roof prototypes were installed; surface temperature of the envelope and temperature and relative humidity of indoor and outdoor air were periodically recorded. Using a comparative method, it was possible to establish and quantify the positive effect of the prototype on the thermal performance of the envelope in local conditions, demonstrating its usefulness.

Keywords: Green roofs, heat transfer, passive cooling, sustainability, thermal comfort.

\section{Telhados verdes como dispositivo de climatização passiva no Trópico}

Resumo

Determina-se o comportamento térmico de um protótipo experimental de telhado verde que possa ser instalado sobre sistemas de coberturas inclinadas em telhas de fibrocimento, amplamente utilizadas em nosso meio. Esta pesquisa demonstrou as vantagens do uso dos telhados verdes como dispositivos de climatização passiva, nas condições climáticas e meteorológicas específicas da cidade de Cali (Colômbia), onde o telhado representa a maior fonte de ganho de calor. Durante a fase experimental, foram construídos um módulo de controle e dois módulos de prova sobre os quais foram instalados os protótipos e registrados periodicamente os valores de temperatura superficial da envolvente e temperatura e umidade relativa do ar exterior e interior. Utilizando um método comparativo, pôde-se estabelecer e quantificar o efeito positivo do protótipo sobre o comportamento térmico da envolvente nas condições locais, demonstrando sua utilidade.

Palavras-chave: conforto térmico, refrigeração passiva, sustentabilidade, telhados verdes, transferência de calor. 


\section{Introducción}

La presente investigación se desarrolló como parte del trabajo de grado para optar por el título de magíster en Arquitectura y Urbanismo de la Universidad del Valle, realizado por autor principal, bajo la tutoría de los dos coautores (Osuna, 2013); su objetivo principal fue desarrollar y evaluar un prototipo de techo plantado que pueda ser utilizado sobre los sistemas de cubierta de tejas onduladas de fibrocemento en el clima de Santiago de Cali, con el propósito de mejorar el confort térmico al interior de los espacios y, por consiguiente, reducir el consumo energético en climatización.

La necesidad del control térmico de los espacios interiores, mediante el manejo adecuado de los procesos de transferencia de calor que se producen de forma natural, ha impulsado el desarrollo de los sistemas pasivos de climatización como una alternativa deseable, en consonancia con la conciencia ambiental que se ha venido desarrollando en la sociedad durante los últimos años.

Las propiedades de enfriamiento y aislamiento térmico de los techos plantados - o techos verdes - han sido demostradas en numerosos proyectos de investigación. Sus ventajas son sin duda numerosas desde el punto de vista ecológico y social. Estos sistemas de cubierta actúan positivamente sobre el clima de la ciudad y su región, así como sobre el clima interior de los edificios bajo su cobijo. Dan protección contra la radiación solar, reducen la fluctuación térmica sobre la superficie exterior del edificio y aumentan su capacidad térmica, contribuyendo al enfriamiento pasivo de los espacios interiores. Gracias a la disminución de las ganancias térmicas, las cubiertas plantadas reducen el consumo de energía y, por ende, el aporte de las viviendas al calentamiento global ${ }^{1}$.

El desempeño térmico de la cubierta influye directamente en el confort de los espacios interiores, mediante los procesos de transferencia de calor por conducción, por convección y por radiación. Las cubiertas verdes participan en el balance térmico de una edificación mediante varios mecanismos, y su desempeño térmico varía según la especie vegetal, el tipo de suelo que se utilice como soporte y las condiciones climáticas del lugar donde se implemente. Debido a esta compleja interrelación entre las condiciones climáticas exteriores y las características propias de masa vegetal, es necesario realizar mediciones específicas en cada región, para evaluar los resultados del comportamiento térmico de diferentes tipos de cubiertas verdes, que permitan inferir valores de diseño climático en edi-

1 De acuerdo con U.S. Energy Information Administration (EIA), del total de la energía consumida por el hombre, cerca del $50 \%$ es utilizada en los edificios, y de este porcentaje el $66 \%$ se consume en climatización, en iluminación y en calentamiento de agua. ficaciones. En la ciudad de Cali, por su cercanía

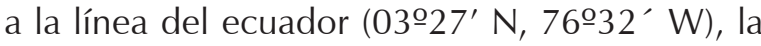
superficie que está más expuesta a la radiación solar en la edificación es la cubierta, pudiendo recibir dicha radiación hasta por doce horas continuas, logrando captar y transmitir una gran cantidad de calor hacia el espacio interior.

\section{Los techos plantados: problemas y perspectivas}

Las edificaciones realizan permanentemente un intercambio térmico con su entorno, determinado principalmente por la radiación solar y la temperatura del aire. La relación entre este intercambio y las propiedades termofísicas de los materiales de construcción componen el desempeño térmico de la envolvente. En los climas cálidos y tropicales como el de Cali, las cargas térmicas son muy altas e inducen a un ambiente no confortable en el interior de edificios.

La modificación del equilibrio de energía en las zonas urbanas ha generado un aumento en la temperatura de las ciudades conocido como "isla de calor urbana" (ICU o UHI), las cuales ya fueron identificadas para la ciudad de Cali (Gamboa, Rosillo, Herrera, López Bernal y Iglesias García, 2011). Este fenómeno se produce, entre otros factores, por la sustitución de áreas verdes con superficies impermeables que limitan la evapotranspiración (Susca, Gaffin y Dell'Osso, 2011), siendo las cubiertas un factor fundamental, ya que constituyen entre el 20 y $25 \%$ de la superficie urbana (Akbari, Menon y Rosenfeld, 2009) y que en el caso de Cali se incrementaron un 29\% entre los años 1984 y 2003 (Santana, Escobar y Capote, 2011) generando cambios en los procesos de transferencia de calor entre la superficie de la tierra y la atmósfera.

En climas cálidos, los techos deben absorber la menor cantidad posible de radiación solar, ofrecer la máxima resistencia al flujo de calor de la cara exterior hacia el interior, tener inercia térmica para reducir las fluctuaciones de temperatura y radiar la menor cantidad posible de energía hacia el interior del recinto. Sin embargo, gran parte de las viviendas de interés social de Cali poseen cubiertas con resistencia e inercia térmica muy bajas, con efectos directos en el confort al interior de los espacios. Las cubiertas inclinadas de fibrocemento son ampliamente usadas en Colombia debido a su estanqueidad, bajo costo y facilidad de instalación. Han sido utilizadas por más de seis décadas y un solo fabricante (Eternit®) ha cubierto más de 300 millones de metros cuadrados con sus tejas.

El comportamiento térmico de una cubierta plantada depende de las interacciones entre los materiales que la componen y los factores climáticos del lugar en que se instala, como son la temperatura, la humedad relativa, la radiación solar, la precipitación, la evapotranspiración y la fotosíntesis. La vegetación realiza simultáneamente 
transferencias de energía mediante procesos de evaporación, de reflexión y de convección, en una constante adaptación a su entorno, de una manera bastante compleja que solo puede ser evaluada mediante la elaboración de modelos.

Los techos plantados son un sistema de enfriamiento pasivo poco estudiado (Theodosiou, 2003), que actúa mediante el proceso de evapotranspiración de las plantas, por lo cual se puede catalogar como un sistema de enfriamiento evaporativo, que adicionalmente provee una muy alta resistencia al flujo de calor hacia el interior de los espacios. El enfriamiento evaporativo puede ser definido basándose en la termodinámica de la evaporación del agua (Santamouris y Asimakopoulos, 1996). Se trata de un proceso que utiliza la energía presente en el aire, para reducir la temperatura de bulbo seco y aumentar la humedad relativa.

La cubierta es, en nuestra latitud, la superficie que mayor ganancia térmica aporta al interior de los espacios, recibiendo el $49 \%$ de la carga térmica por radiación (Olgyay, 1968). Una manera de minimizar los impactos de la radiación solar sobre la cubierta consiste en disponer de una gran masa de material en el techo, que sea capaz de almacenar el calor captado, que retarde la transmisión de calor al interior y de esa forma logre que este se disipe en el exterior. Este efecto se logra fácilmente por la masa vegetal. En estado permanente, la alta resistencia térmica de las cubiertas plantadas reduce el flujo de calor desde el exterior hacia los espacios interiores.

La vegetación tiene la capacidad de recibir grandes cantidades de radiación solar directa, aprovechándola para transformar y asimilar sus nutrientes por medio de la fotosíntesis, tomando la energía solar necesaria y transmitiendo la excedente. La transpiración de la planta contribuye a la reducción de la temperatura por medio del enfriamiento evaporativo al transmitir calor de la hoja por evaporación, enfriando la superficie de la planta y el entorno inmediato a esta, $y$, por tanto, enfriando el interior de la construcción. Del total de la energía solar incidente y dependiendo de la longitud de onda, las plantas absorben para la fotosíntesis entre el 5 y el $20 \%$, reflejan entre el 5 y el $20 \%$, disipan por evapotranspiración entre el 20 y $40 \%$, emiten entre el 10 y el $15 \%$ y transmiten únicamente entre el 5 y el $30 \%$ (Bansal, 1994). La radiación solar recibida por la cubierta produce más de un tercio de la ganancia térmica del interior de una vivienda. Sin embargo, su misma proporción la convierte en el elemento más importante para transferir calor hacia la bóveda celeste durante la noche. Así, al controlar la radiación solar que recibe la cubierta, se puede controlar efectivamente el confort climático al interior del edificio.

Las investigaciones sobre techos plantados han venido en aumento durante las últimas décadas, como una estrategia bioclimática para mejorar la eficiencia energética de los edificios. Los trabajos de Mentens, Raes y Hermy (2006), Oberndorfer et al. (2007) y Alexandri y Jones (2008) se han enfocado hacia el potencial de la vegetación en las cubiertas, para resolver problemas del entorno urbano como el control y la retención de la escorrentía urbana, la mitigación de los efectos de isla de calor urbana (UHI), el aumento de las áreas verdes y la creación de nuevos ecosistemas urbanos.

Las más recientes investigaciones científicas sobre el comportamiento térmico de techos con vegetación sugieren que las características físicas y biológicas de las plantas son las responsables de absorber un gran porcentaje de la radiación solar entrante, generando enfriamiento pasivo en la envolvente. La interacción entre el albedo de la vegetación, el sombreado producido por las hojas de las plantas y la baja difusividad térmica de la capa de suelo de siembra generan reducción de las temperaturas superficiales y disminución del flujo de calor en el interior de la edificación a través de la cubierta (Niachou, Papakonstantinou, Santamouris, Tsangrassoulis y Mihalakakou, 2001).

El comportamiento de los techos plantados ha sido estudiado de manera teórica, experimental o por la combinación de ambos enfoques. Sin embargo, todos los esfuerzos en su mayoría han evaluado las propiedades térmicas de techo verde en condiciones estables o por modelos computacionales. Los datos cuantitativos sobre este tema siguen siendo necesarios para muchas condiciones climáticas específicas.

Las investigaciones realizadas por Kotsiris, Androutsopoulos, Polychroni y Nektarios (2012), Ayata, Tabares-Velasco y Srebric (2011), Parizotto y Lamberts (2011), Lazzarin, Castellotti y Busato (2005), Tabares-Velasco y Srebric (2011), Wong, Chen, Ong y Sia (2003), Hodo-Abalo, Banna y Zeghmati (2012) y Onmura, Matsumoto y Hokoi (2001) se encaminan a determinar el comportamiento térmico de las cubiertas plantadas en condiciones específicas, ya sea en función de las condiciones climáticas del lugar o de la metodología utilizada.

A pesar de la multitud de enfoques con los que han sido estudiados, las investigaciones en su gran mayoría han examinado los techos verdes como la sumatoria de los materiales que lo componen, en lugar de considerarlos en su conjunto como un sistema. De esta manera, se subestiman los procesos de circulación de aire y evapotranspiración que suceden al interior del sistema. Concretamente, los datos experimentales resultantes del uso del "Cold Plate" (Tabares-Velasco y Srebric, 2011), demuestran que los procesos de evapotranspiración son bastante complejos y que dependen de factores tales como la densidad de las hojas (índice de área foliar), la radiación de onda corta y el contenido de agua en el sustrato. Dependiendo de las 
plantas y las condiciones ambientales, la evapotranspiración controla la intensidad de los flujos de calor en ambas direcciones. En ese sentido, las investigaciones en laboratorio están obligadas a la utilización de configuraciones experimentales muy complejas, incapaces de simular totalmente las condiciones meteorológicas cambiantes de un lugar específico y, simultáneamente, medir los flujos de evaporación con una precisión suficiente para determinar su papel en los mecanismos de transferencia de calor. Los análisis en túnel de viento pretenden simular el transporte simultáneo de calor y humedad que realiza la vegetación en una cubierta verde. Durante el periodo de indagación solo se encontraron dos experimentos de laboratorio que utilizaran túneles de viento y en ninguno de los casos lograron medir las tasas de evapotranspiración de forma continua y confiable. (Bell y Spolek, 2009; Onmura et al., 2001).

Las mediciones experimentales siguen siendo la manera más confiable para evaluar y predecir el comportamiento térmico de los techos verdes en determinadas condiciones climáticas. Es cuestionable la fiabilidad de los estudios que utilizan modelos de balance de energía, debido a que excluyen las variables biológicas y los procesos realizados por las plantas (fotosíntesis y evapotranspiración), aunque ofrecen indicativos racionales y rápidos sobre el desempeño térmico que sirven como pautas para los desarrollos experimentales (Feng, Meng y Zhang, 2010; Jim y He, 2010; Niachou et al., 2001; Tsang y Jim, 2011). Se considera que el enfoque experimental es el más adecuado para este caso, debido a su fiabilidad y sencillez para la medición del comportamiento térmico del prototipo en condiciones reales y dinámicas. Su eficiencia y confiabilidad ha sido demostrada en los trabajos realizados en la Universidad de Colima en México (Fajardo, 2005; Gameros, 2007; Haro, 2009; Sánchez, 1993) y en la Universidad Internacional de Andalucía (González, 2011), en los cuales se ha evaluado el desempaño térmico de diferentes sistemas de climatización pasiva mediante la utilización de módulos de prueba en contextos socioculturales y económicos similares a nuestro caso de estudio.

\section{Metodología}

En esta investigación se utilizó una metodología experimental-descriptiva para evaluar diferentes variables a partir de experimentos de campo con el propósito de comprobar unas hipótesis establecidas. A fin de alcanzar los objetivos propuestos, se evaluó el desempeño térmico de un sistema de cubierta de las láminas onduladas de fibrocemento, comparándolo con dos sistemas de techos plantados, sobrepuestos sobre el mismo tipo de cubiertas.

Este enfoque cuantitativo, mediante la toma de datos, la realización de cálculos numéricos y simulaciones computacionales, permitió estable- cer parámetros de comportamiento térmico de las cubiertas plantadas y verificar de qué manera estos sistemas contribuyen a mejorar el confort térmico al interior de las edificaciones en las condiciones climáticas específicas de Cali.

Se estudió el comportamiento térmico de un prototipo de techo plantado con dos tipos de coberturas vegetales (Ajuga reptans y Arachis pintoi), comparando su desempeño con el sistema tradicional de tejas de fibrocemento, ampliamente utilizadas en la región. Se realizaron registros de temperatura del aire y humedad relativa al interior los tres módulos, durante nueve semanas (14 de marzo al 16 de mayo de 2013) con frecuencia horaria, comparándolos entre ellos y con los datos de temperatura y humedad relativa exterior.

\section{Modelos experimentales}

Para la realización de esta investigación se construyeron tres celdas o módulos de medición, los cuales se ubicaron tomando en cuenta condiciones exteriores similares, de asoleamiento, ventilación y radiación. Una primera celda sirvió como módulo de control o testigo, y las otras dos celdas sirvieron como módulos experimentales sobre los cuales se instalaron dos prototipos de techos plantados. Los módulos experimentales y el módulo de control son exactamente iguales en forma, tamaño, dimensión, materiales, color exterior y orientación para garantizar que la carga térmica sea idéntica en cada uno de ellos, para así poder evaluar su funcionamiento determinar de manera comparativa el potencial de enfriamiento de cada uno de los experimentos realizados.

Las celdas experimentales se construyeron en la sede Meléndez de la Universidad del Valle en Cali, cuidando que las relaciones de sus envolventes con el medio ambiente fueran lo más similares posibles, diferenciándolas únicamente por el sistema de techo con que están cubiertas. Son pequeñas construcciones de base cuadrada con unas dimensiones exteriores de 1,22 $\mathrm{m} x$ 1,22 m, con una altura mínima de 1,08 m, levantadas de la losa de apoyo mediante bastidores de madera. Para los cerramientos laterales se utilizó un sistema multicapa de muro liviano seco, conformado por un entramado en lámina metálica galvanizada, la cara exterior en placa de fibrocemento de 6 milímetros de espesor y una capa de $14 \mathrm{~mm}$ de poliestireno expandido al interior como aislante térmico. Se consideró que de esta manera se produciría poco flujo de calor por las paredes y el piso, con el fin de facilitar la evaluación de los diferentes tipos de cubierta (Figura 1).

La cubierta de cada módulo se construyó en teja ondulada de fibrocemento perfil 5 (Ruralit), con una pendiente del $25 \%$, apoyadas sobre los muros, obteniendo una altura al interior del módulo de 1,08 m en el punto más bajo. La configuración de estos módulos de experimentación 
simula las proporciones de un espacio típico de una vivienda de interés social de Cali, pero no pueden considerarse un modelo a escala ya que no poseen elementos que faciliten la ventilación natural y la renovación de aire tales como puertas y ventanas.

Sobre la cubierta de los dos módulos experimentales se instalaron dos prototipos de sistemas de cobertura vegetal que difieren en la especie utilizada así: Ajuga o Lechuguilla (Ajuga reptans) y maní forrajero (Arachis pintoi), ambas del tipo rastrero, muy comunes en la región y con supuestos bajos requerimientos de agua.

\section{Instrumentos de medición}

Para la captura de datos de temperatura del aire y humedad relativa se utilizaron instrumentos de medición y adquisición de datos tipo datalogger marca Extech (RHT10). Para la toma de datos de temperatura superficial se utilizó un termómetro infrarrojo Extech 42510A, que detecta la energía emitida, reflejada y transmitida.

Con los valores de temperatura superficial, tomados aleatoriamente, se pudo inferir la temperatura media radiante al interior de los módulos.

Procedimiento experimental. Para evaluar los prototipos propuestos se siguió el siguiente proceso de registro, procesamiento y análisis de la información:

1. Primero se realizó la calibración de los dataloggers bajo las mismas condiciones, durante un día completo.

2. Se hizo una medición de estabilización térmica con el fin de verificar que los tres módulos presenten condiciones similares.

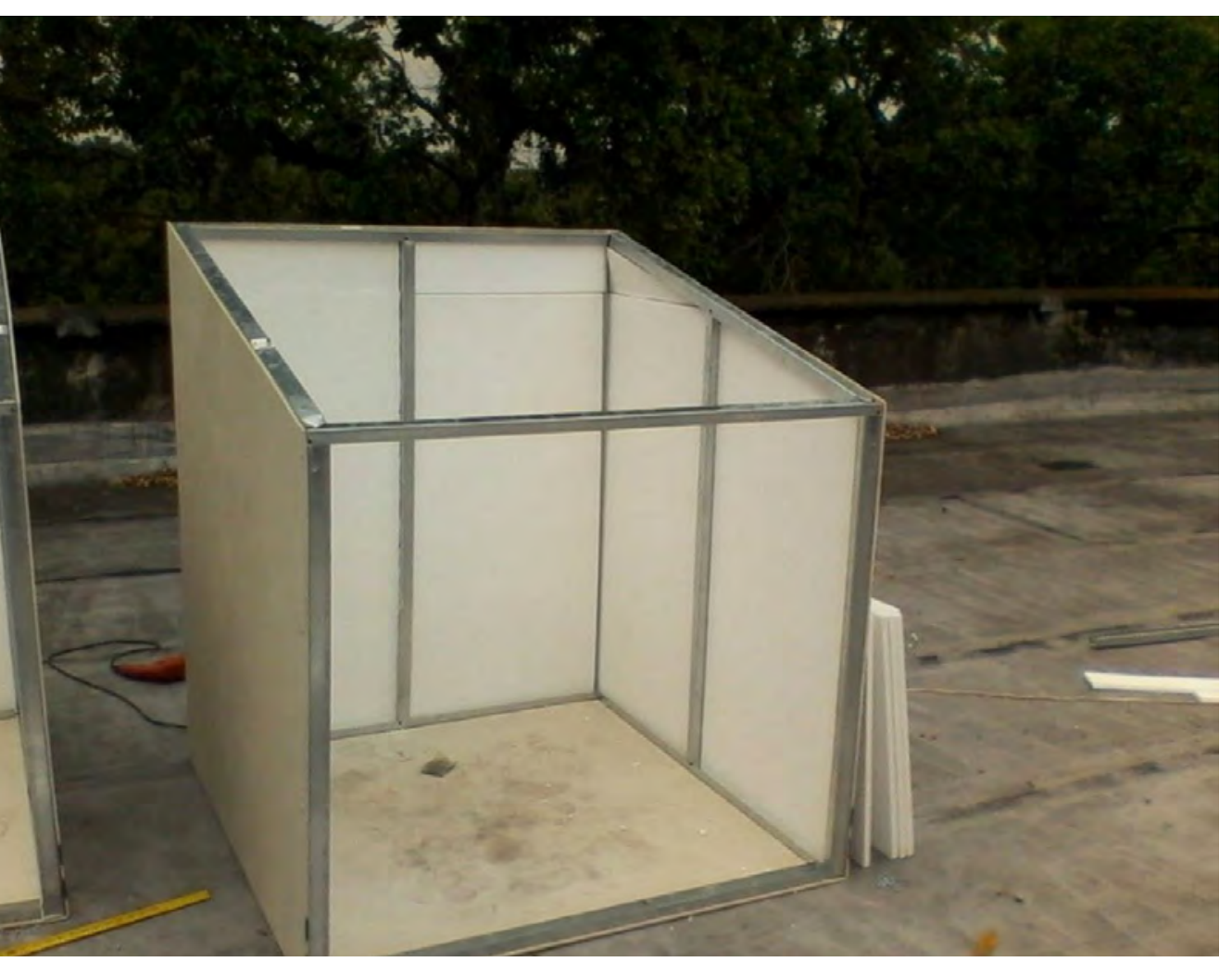

(A) Figura 1. Vista interior del módulo de experimentación

Fuente: elaboración propia, 2013.
3. Durante el periodo de evaluación del sistema se programan los dataloggers para que realicen y capturen registros cada hora, temperatura de bulbo seco (TBS) y de humedad relativa (HR).

4. Se ubica un datalogger al interior de cada uno de los tres módulos experimentales y uno adicional para registrar los datos exteriores. Con este fin se fabricó un dispositivo que permita que el equipo permanezca ventilado y protegido de la radiación solar y así evitar que los datos se alteren por algún agente externo.

5. La información registrada por los equipos es descargada a través del software específico de Extech RHT10 semanalmente, para luego ser transcrita a tablas de Excel.

6. Una vez procesados todos los datos se realizan los gráficos de curvas de temperatura y humedad relativa necesarios para el estudio y análisis comparativo de cada uno de los prototipos y del módulo testigo.

7. Se hace una evaluación de los resultados en función de los objetivos específicos planteados en la investigación

8. Por último, se realizan las conclusiones respectivas.

Análisis del comportamiento módulos experimentales. Se utilizaron dos tipos de mediciones de los módulos. En primer lugar, se tomaron los datos meteorológicos oficiales del Instituto de Hidrología, Meteorología y Estudios Ambientales (Ideam), complementados por los datos disponibles en la web de las bases de datos de la Red Meteorológica Automatizada de Cenicaña. Se realizó una caracterización climática por computador utilizando el programa Climate Consultant Versión 5.4 (UCLA, 2013), con el fin de verificar la precisión de los archivos climáticos EPW disponibles para la realización de las simulaciones de desempeño térmico. Se confirmó la precisión de los archivos climáticos EPW obtenidos del Departamento de Energía de Estados Unidos, lo cual permite realizar simulaciones del desempeño térmico de los módulos de prueba antes de realizar las mediciones experimentales.

Los datos que alimentan el programa y los registros obtenidos de Cenicaña presentan diferencias considerables en las variables de viento y precipitación, pero muy poca diferencia en las variables de temperatura y humedad relativa.

En segundo lugar, se capturan los datos al interior de los módulos experimentales y su relación con el módulo de control y la temperatura exterior, como mejoras para las condiciones de confort térmico. Con ese propósito se evalúan tres componentes: las temperaturas características, el desempeño térmico de los dispositivos y el confort térmico humano al interior de los módulos.

Temperaturas características. El análisis comparativo de los valores de temperatura del aire con los valores correspondientes en el módulo 
de referencia y el ambiente exterior constituye la forma inicial de caracterizar el comportamiento térmico de los prototipos.

Las características del módulo testigo (con igual configuración a la de los módulos experimentales, pero sin protección adicional en la cubierta) nos permiten deducir el efecto del techo plantado en el desempeño térmico de la cubierta.

Un sistema de enfriamiento pasivo será eficiente en la medida que logre reducir las temperaturas máximas, medias y mínimas en relación con las temperaturas del módulo de control. Cuanto mayores sean estas diferencias mayor será la eficiencia de enfriamiento. Se espera que la temperatura media interior en el módulo experimental sea inferior a la observada en el módulo de control. También es importante lograr la menor amplitud de temperatura posible en el interior del módulo experimental.

Desempeño higrotérmico de los prototipos. Por comparación, los datos obtenidos sirvieron para realizar un análisis del comportamiento higrotérmico de los sistemas de techos plantados ubicados sobre los módulos de monitoreo. Dadas las características de los módulos experimentales referentes a sus dimensiones debe hacerse una interpretación de los datos obtenidos para que sean válidos en espacios habitables de dimensiones típicas. La relación entre el área expuesta y el volumen de aire interior genera que los módulos de prueba presenten unas condiciones menos favorables en comparación con un espacio habitable de mayores dimensiones (Sánchez, 1993).

Confort térmico. La eficiencia energética se puede definir como la energía que necesita un edificio para mantener unas adecuadas condiciones de confort. El requerimiento principal para conseguir el confort térmico en un individuo es que su balance energético sea nulo, o casi nulo. La temperatura es quizá el parámetro más relevante en el balance energético (temperatura de bulbo seco, temperatura radiante, temperatura operativa y sensación térmica). La humedad relativa y la velocidad del aire también forman parte de los parámetros físicos que determinan el confort. Asimismo, se deben considerar los parámetros individuales de confort térmico que tienen que ver con la persona, como son la vestimenta, la tasa metabólica, la edad y el sexo. Aunque estos factores tienen una relevancia menor que los parámetros físicos descritos anteriormente, no se puede obviar su impacto.

Para evaluar los rangos de confort térmico en edificios se puede optar por el método del confort predictivo (voto previsto medio), que en la actualidad es quizá el más extendido para la estimación del confort térmico, o el modelo de con- fort adaptativo (Humphreys, Auliciems, Griffins, entre otros), que tiene en cuenta la capacidad de los ocupantes de adaptarse al clima exterior.

En líneas generales, se puede decir que el modelo de Fanger es adecuado para los edificios acondicionados mecánicamente, siendo el modelo adaptativo más apropiado para evaluar el confort en edificios climatizados con estrategias pasivas de calefacción o ventilación. Actualmente no contamos con datos científicos sobre el rango de confort térmico para el clima específico de la ciudad de Cali, pero las investigaciones recientes realizadas en Venezuela (Morales y Cruz, 2003) muestran que los usuarios de los edificios naturalmente ventilados tienen una preferencia de confort por encima de los estándares propuestos, y la sensación térmica de los individuos está muy ligada a la temperatura media que ellos experimentan.

\section{Resultados}

\section{Desarrollo de la experimentación}

Adaptando las experiencias de otros países a las condiciones climáticas locales, y sobre la base de utilizar materiales de fácil consecución en nuestro medio, se plantea un prototipo que funcione para ser sobrepuesto a las cubiertas inclinadas de fibrocemento. Normalmente, los sistemas de techos plantados están compuestos por un soporte estructural, una impermeabilización, los proyectores de raíz, el drenaje, los filtros, el medio de crecimiento y la vegetación.

Para reducir al mínimo el peso del sistema y mantener el concepto de techo liviano, se propone que algunos elementos cumplan varias funciones. Así, el soporte estructural y la impermeabilización son resueltos por la propia cubierta de fibrocemento, sobre la cual se instala el sistema conformado por unas bandejas de aluminio de $52 \times 32 \times 8 \mathrm{~cm}$, de fácil consecución en el mercado, que cumplen la función de protección antirraíz, en el fondo de las cuales se realizaron perforaciones para garantizar el drenaje. Como filtro se utiliza espuma fenólica de célula abierta, de gran absorción, que ayuda a mantener el contenido del agua.

Sobre estos elementos se sembró la vegetación en condiciones controladas para garantizar su crecimiento. Al cabo de tres semanas se consiguió la cobertura vegetal necesaria para poder comenzar la etapa de mediciones. Las Figuras 2 y 3 muestran el estado de desarrollo del follaje de los prototipos, justo antes de ser instalados sobre los módulos experimentales.

Las bandejas de aluminio plantadas se instalan sobre las ondulaciones de la teja de fibrocemento (Figura 4), cubriendo toda la superficie de la cubierta de los módulos experimentales. 


\section{Calibración}

Para garantizar la confiabilidad de los datos durante el periodo de experimentación, se realizó un proceso de calibración tanto de los instrumentos de medición y captura de datos como de los módulos de análisis. Los datos obtenidos permitieron observar que las diferencias entre los distintos equipos no superaban el margen de precisión determinado por los fabricantes. Para calibrar los módulos experimentales se realizó una simulación en Ecotect Analisys 2011, que permitió determinar que la ubicación propuesta garantizaba condiciones similares de asoleamiento en los tres casos. Se mantuvieron los tres módulos con las mismas características físicas, con el fin de verificar que tuvieran un comportamiento térmico similar (Figura 5).

Los registros mostraron que los tres módulos presentaban condiciones similares de transferencia de calor con el exterior, ya que los datos obtenidos muestran una muy pequeña variación en los valores de temperatura y humedad relativa al interior de los mismos.

La etapa de monitoreo se llevó a cabo durante nueve semanas, entre el 14 de marzo y el 16 de mayo del 2013. Este periodo incluyó el equi-

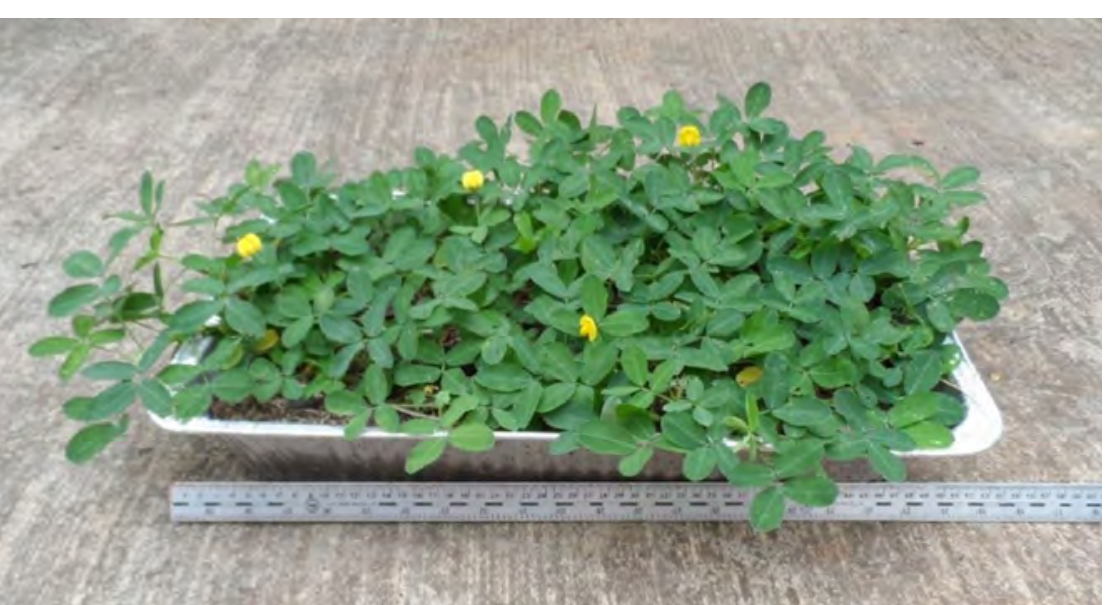

(A) Figura 2. Prototipo con maní forrajero

Fuente: elaboración propia, 2013. noccio de primavera y, por tanto, los días en los cuales la cubierta recibe un mayor porcentaje de la radiación solar directa. Se presentó una inusual temporada seca seguida de la tradicional temporada lluviosa, lo cual permitió evaluar el comportamiento de los módulos experimentales durante las dos condiciones climáticas típicas de Cali. Al inicio del periodo de monitoreo, los dispositivos de techo plantado se encontraban en condiciones ideales de humedad e índice foliar, ya que la vegetación se había desarrollado en condiciones óptimas de riego y sombreado (Figura 6).

Se tomó la decisión de no utilizar ningún tipo de riego adicional, para evaluar la resistencia de los prototipos a las condiciones climáticas propias del lugar.

Durante las primeras dos semanas (marzo 14 al 27), se presentó una alta precipitación con un promedio diario de $6,38 \mathrm{~mm}$, lo cual favoreció las condiciones de humedad del sustrato y mantuvo las condiciones ideales de la vegetación.

En la segunda quincena (marzo 28 a abril 10) se presentó un inesperado tiempo seco, con una precipitación acumulada de tan solo 1,9 mm, con un promedio de apenas $0,3 \mathrm{~mm}$ diarios. Este factor, sumado a las elevadas temperaturas registradas, afectó negativamente las condiciones de las plantas que se marchitaron completamente y permitieron la evaporación de casi la totalidad del contenido de agua en el sustrato de los prototipos.

Entre el 11 y el 24 de abril se presentó un fuerte cambio en las condiciones climáticas, regresando los días lluviosos, con una precipitación de 175 $\mathrm{mm}$, que representa casi el triple de lo esperado durante esta época. Las fuertes lluvias permitieron recuperar el contenido de humedad en el sustrato de los prototipos, mejorando las condiciones para la recuperación de la vegetación. Las plantas de ajuga, que habían resistido mejor las condiciones secas, comenzaron lentamente la recuperación de su follaje. Adicionalmente, aparecieron

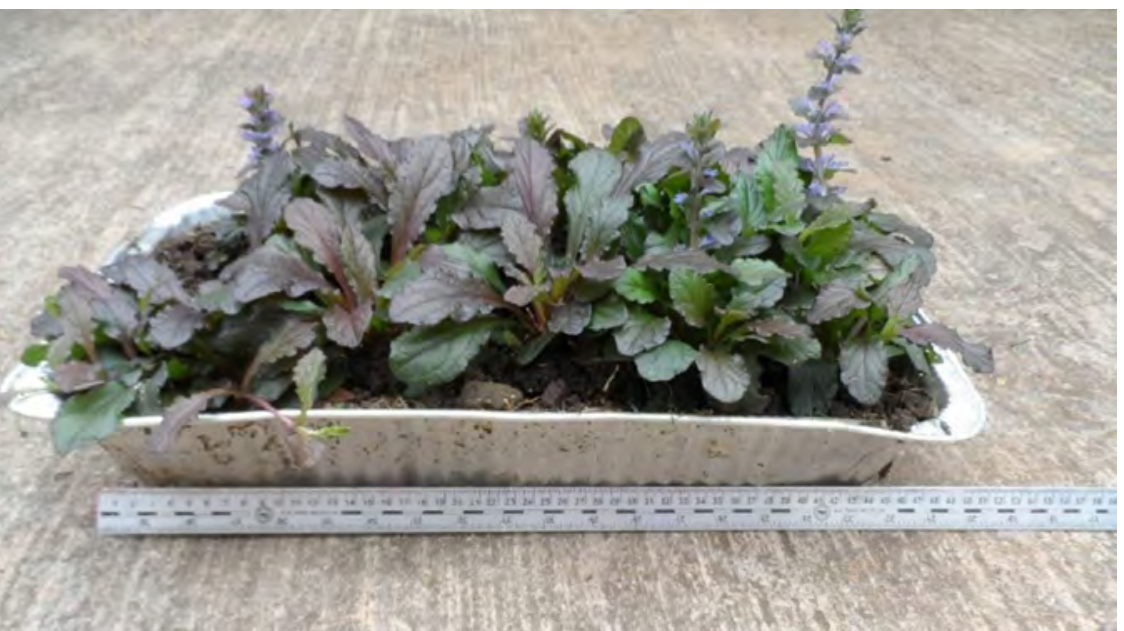

(A) Figura 3. Prototipo con ajuga

Fuente: elaboración propia, 2013.

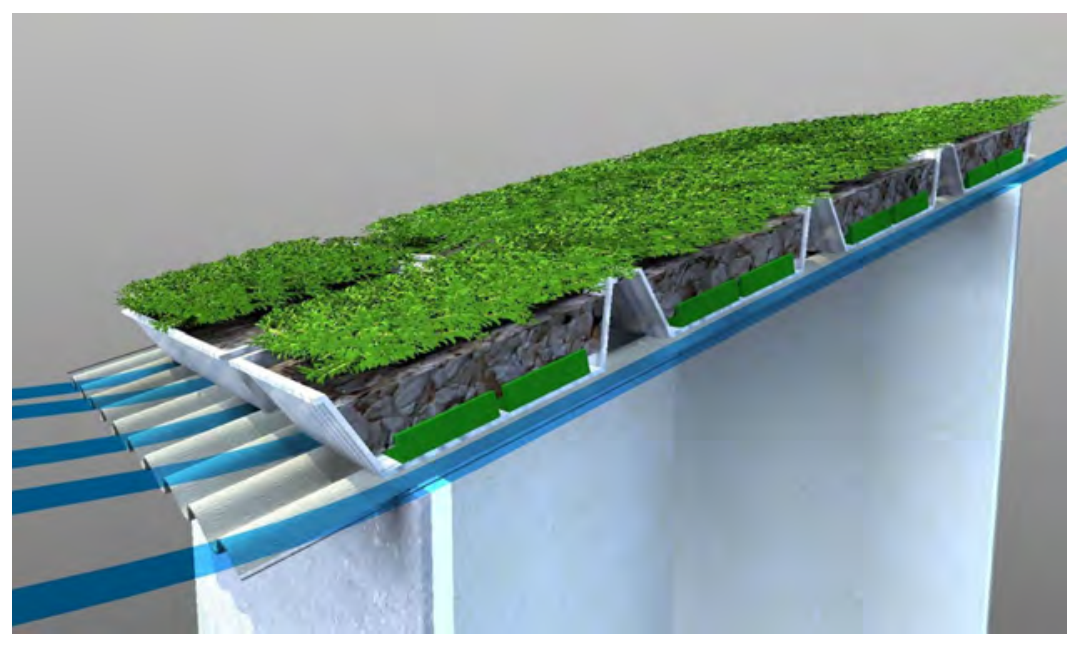

(A) Figura 4. Esquema de funcionamiento del dispositivo Fuente: elaboración propia, 2013. 
de manera espontánea nuevas plantas. Por su parte, el maní forrajero, que no había sido tan resistente a la sequía, perdió todas sus hojas y su proceso de recuperación se realizó muy lentamente.

Durante el último periodo de experimentación (abril 26 a mayo 16) se mantuvieron las condiciones climáticas lluviosas precedentes, alcanzando un promedio de precipitación de $9 \mathrm{~mm}$ diarios, con máximos de hasta $69 \mathrm{~mm}$ como el registrado el día 15 de mayo. Las fuertes lluvias permitieron que los prototipos mantuvieran su nivel de humedad en el sustrato, lo que hizo posible una continua recuperación de las condiciones de la vegetación. Las plantas de ajuga lograron una cobertura del $70 \%$ de la superficie del prototipo, mientras las de maní apenas alcanzaron un follaje del $20 \%$.

\section{Desempeño térmico}

Durante las nueve semanas de experimentación, el comportamiento térmico de los dos prototipos de cubierta plantada fue muy similar, presentando diferencias muy bajas en el desempeño, especialmente al inicio de las mediciones.

Durante el día, el interior del módulo testigo registró una temperatura del aire muy superior a la temperatura exterior (Figura 7). Las ganancias térmicas presentadas por la envolvente desde el amanecer no son eliminadas y se van acumulando con el transcurso del día, ya que los módulos no cuentan con elementos que permitan realizar ventilación natural ni renovación de aire, y sus paredes están recubiertas al interior con aislantes térmicos. Se realiza muy poca transferencia de calor por las paredes y el piso, pero muy alta por la cubierta. Así, el calor ganado por la cubierta no puede ser transferido nuevamente al exterior por las paredes ni por el movimiento de aire, lo cual eleva considerablemente la temperatura al interior de los módulos.

${ }^{\circ} \mathrm{C}$

50

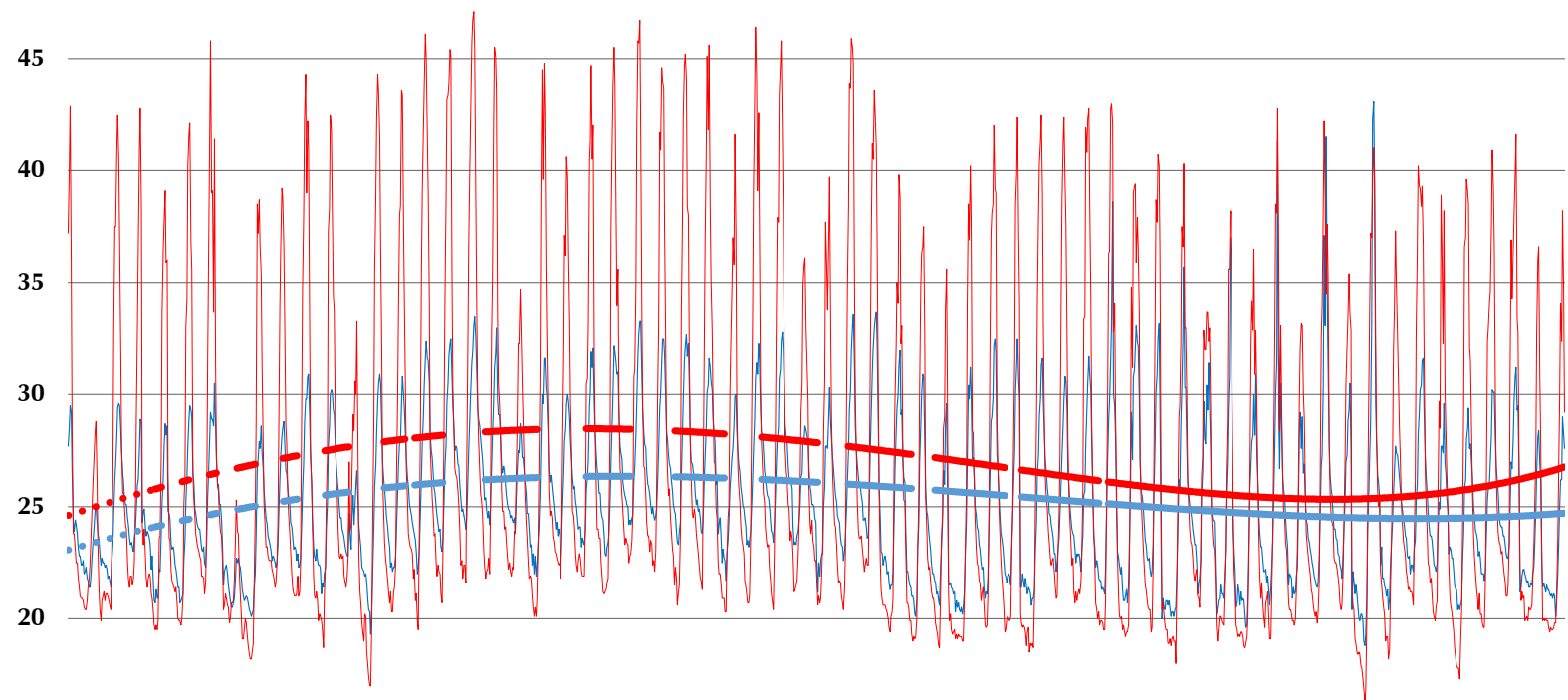

15

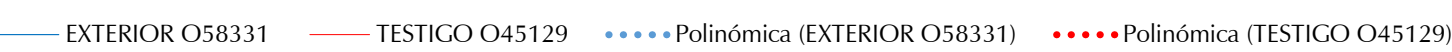

También se debe considerar que las condiciones climáticas al interior de un módulo pequeño son menos favorables que en uno de mayores dimensiones, construido con los mismos materiales, debido a que el módulo pequeño posee una mayor área expuesta que el grande por cada unidad de volumen de aire interior y, por tanto, presentará un mayor incremento en la temperatura del aire en un lapso de tiempo determinado.

El prototipo con maní forrajero presentó un mejor desempeño térmico durante las primeras dos semanas, cuando tenía un muy buen índice foliar y lograba cubrir el $100 \%$ de la superficie del sustrato, mientras que las plantas de ajuga solo cubrían el $80 \%$.
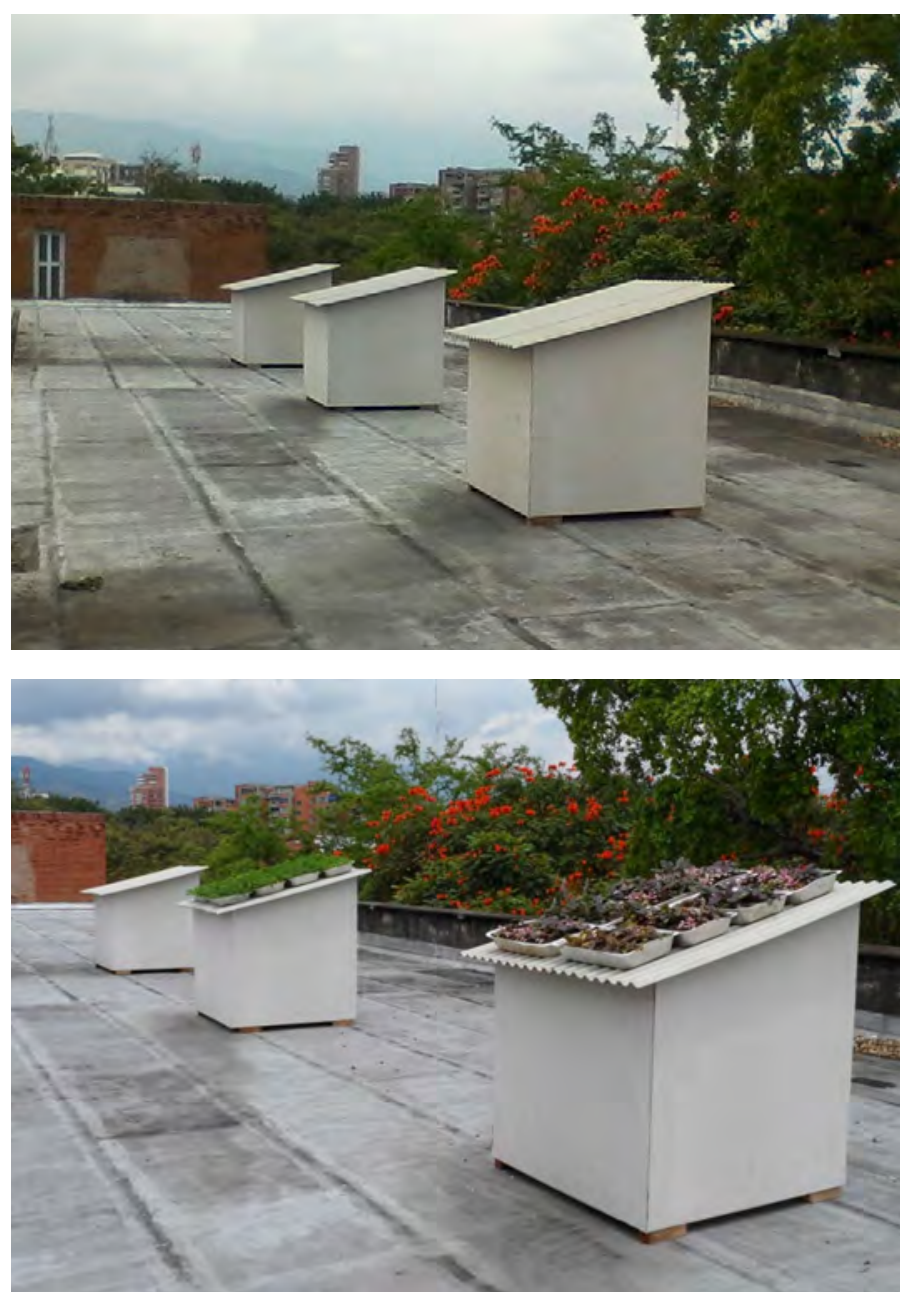

(A) Figura 6. Módulos experimentales durante el monitoreo

Fuente: elaboración propia, 2013.
\& Figura 7. Temperatura exterior y módulo testigo Fuente: elaboración propia, 2013. 
$\rightarrow$ Figura 8. Comparativo de la evolución del registro de la temperatura media horaria

Fuente: elaboración propia, 2013.
${ }^{\circ} \mathrm{C}$

Temperatura media horaria

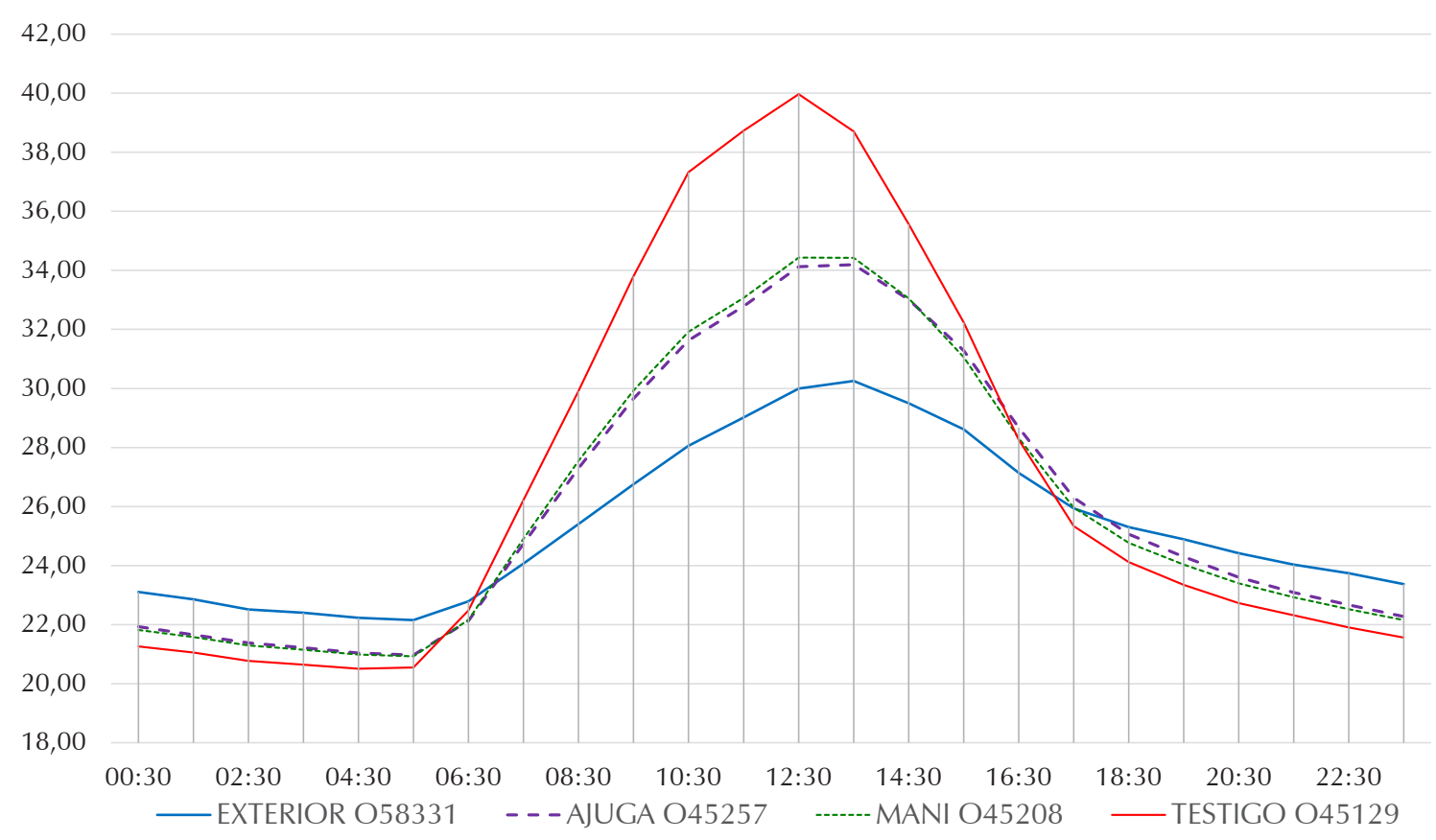

Porcentaje de reducción

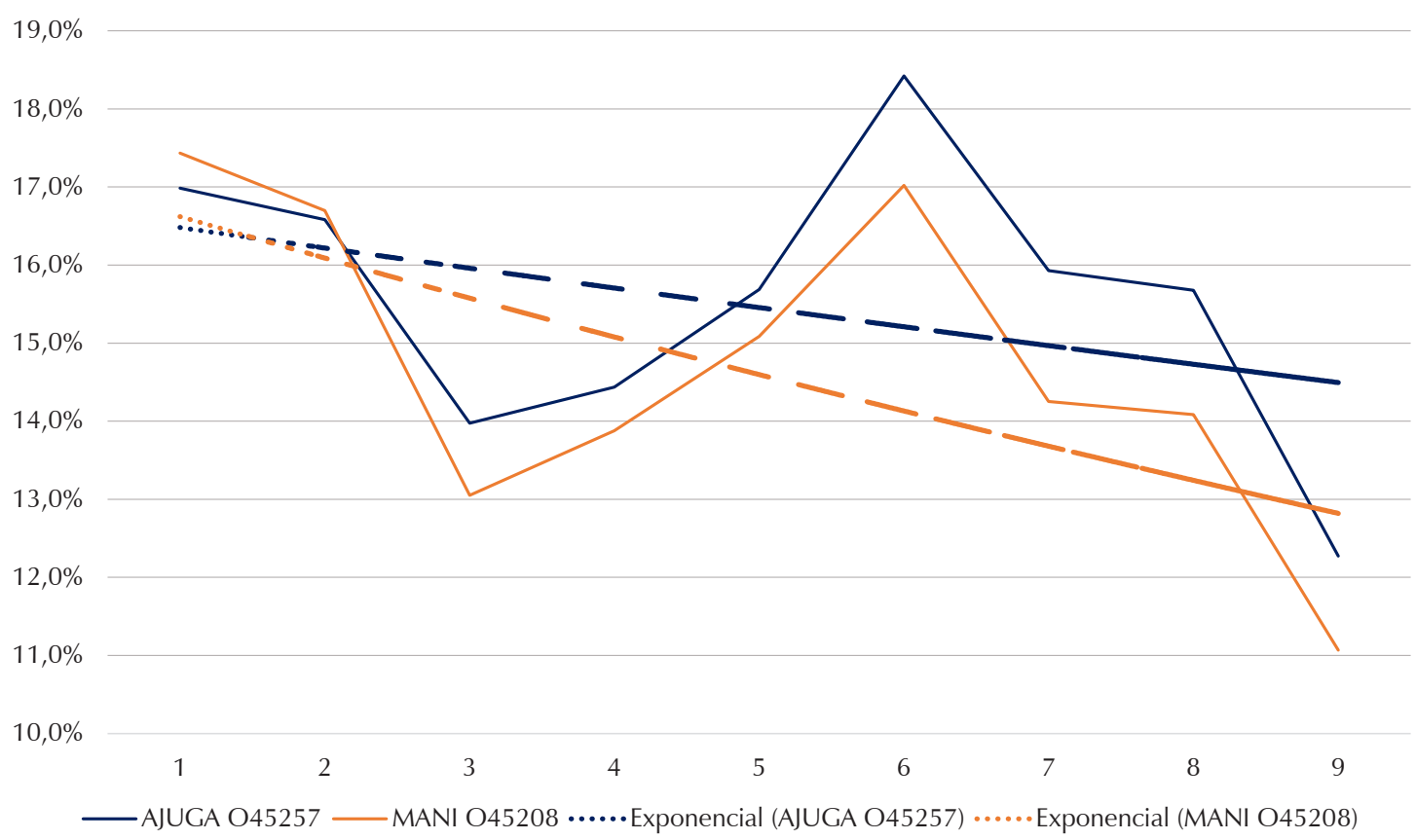

$\geqslant$ Figura 9. Porcentaje de la reducción de la temperatura en módulos experimentales

Fuente: elaboración propia, 2013.

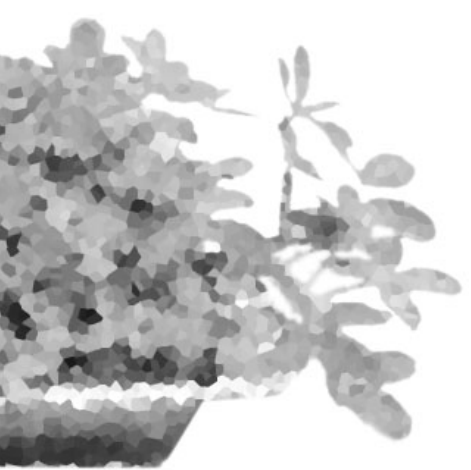

Durante el periodo más seco y los días siguientes, cuando todas las plantas habían perdido su follaje y los sustratos de encontraban completamente expuestos a la radiación solar, la eficiencia de los prototipos fue la más similar, debido a la ausencia de follaje, volviendo casi idénticas las condiciones de los dos módulos experimentales. También se pudo apreciar, que durante ese mismo periodo se presentó la menor eficiencia relativa de los dispositivos. La pérdida del follaje conllevó la pérdida del sombreado del sustrato y como consecuencia se evaporó el contenido de humedad y disminuyó la resistencia térmica del mismo.

Con la llegada de los días lluviosos, los dispositivos recuperaron su contenido de humedad y las plantas comenzaron a recobrar su condición. Lentamente fue apareciendo un nuevo follaje, especialmente en los dispositivos plantados con ajuga.
El maní forrajero prácticamente se secó y no logró recuperarse, pero en su lugar aparecieron nuevas especies de manera espontánea, comenzando a cubrir los sustratos. Los promedios de temperatura horaria registrados durante las nueve semanas (Figura 8) muestran que la temperatura al interior del módulo testigo alcanza a estar $10^{\circ} \mathrm{C}$ por encima de la temperatura exterior al medio día y se igualan hacia las 6:00 a.m. y las 5:00 p.m.

El porcentaje de reducción de la temperatura de los dos módulos experimentales en relación con el módulo testigo durante las nueve semanas en las que se realizaron mediciones se puede apreciar en la Figura 9. Inicialmente, las dos alternativas de vegetación producían casi el mismo porcentaje de reducción de la temperatura, pero con el paso del tiempo, el módulo protegido con maní forrajero se hizo menos eficiente. 


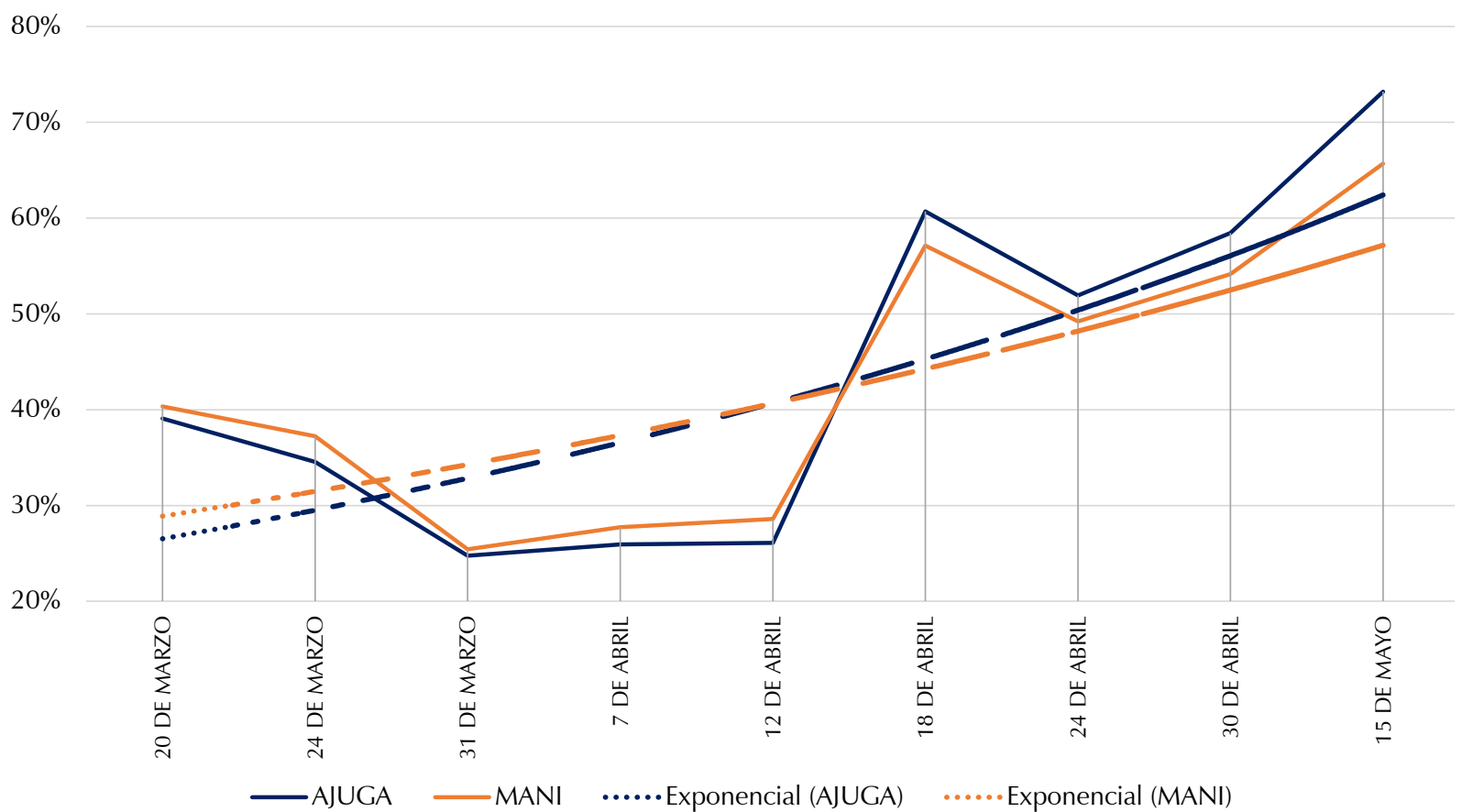

\section{Eficiencia relativa}

Sánchez (1993) establece el concepto de eficiencia relativa como un parámetro que permite determinar la capacidad de enfriamiento de diferentes cubiertas y su potencial de control del clima interior. Este concepto ha sido reutilizado y validado por otros investigadores (Fajardo, 2005; Gameros, 2007; Haro, 2009) en estudios experimentales que se basan en análisis comparativos de módulos a escala. Se define como la fracción de ahorro de energía lograda por el módulo experimental con cubierta plantada, en relación con el módulo testigo sin cubierta plantada (Figura 10).

La comparación en la eficiencia de los módulos se realiza en grados-hora, que son todas aquellas temperaturas horarias que se encuentren por encima de la temperatura (temperatura base) en la cual se hace necesario utilizar sistemas de climatización activos o mecánicos. Esto supone que la cantidad de calor excedente representada por los grados-hora del módulo experimental fuera extraída por medios que consumen energía convencional.

Para determinar la temperatura base se utilizó el concepto de temperatura de neutralidad establecida por Humphreys y Nicol (Humphreys y Nicol, 2002) en su modelo de confort adaptativo en modo pasivo:

\section{Tc $=13,5+0,54$ Tprom}

donde:

Tc $=$ Temperatura de confort

Tprom $=$ Temperatura promedio exterior de bulbo seco

El valor de temperatura promedio $\mathrm{T}_{\text {prom }}$ se calculó con los datos oficiales de temperatura media mensual publicados por el Ideam, los cuales determinaron una temperatura de neutralidad de $26,4{ }^{\circ} \mathrm{C}$ como promedio de los meses de marzo, abril y mayo, periodo durante el cual se desarrolló la etapa experimental.

Esta metodología permite determinar el porcentaje de ahorro energético en enfriamiento logrado por el sistema de cubierta vegetal, suponiendo que de no existir la protección de la cubierta, el módulo hubiese sido enfriado con un sistema de enfriamiento activo (aire acondicionado).

\section{Temperatura media radiante (TMR)}

Mediante el uso de termómetro infrarrojo se tomaron datos de la temperatura de las superficies que conforman la envolvente de los prototipos, para calcular la temperatura radiante media. La Tabla 1 muestra los datos de temperatura emitida que se registraron el día 22 de marzo a las 10:30 a.m. En los tres módulos, la temperatura del aire al interior de los espacios está por encima de la TMR calculada, debido a la ganancia térmica que se ha venido dando desde el inicio del día, y que no ha podido ser transferida el exterior por causa de la nula de ventilación.

El 9 de abril a las 5:30 p.m. (Tabla 2), los valores de TMR calculada estaban por encima de los valores de temperatura del aire registrada por los dataloggers al interior de los módulos. A esa hora del día, la temperatura al interior de los tres módulos se iguala con la temperatura exterior, en un proceso de pérdida de la ganancia térmica que se inicia desde el mediodía.

La temperatura en las caras internas de los muros de los diferentes módulos varía a pesar de tener exactamente las mismas condiciones de exposición a la radiación solar. Este fenómeno se produce porque la cubierta, que sí es diferente en los tres módulos, transfiere calor hacia el espacio interior, calentando el aire, que a su vez calienta los muros. Por esa razón, las caras internas de las paredes del módulo testigo presentan una temperatura mayor
Figura 10. Variación de la eficiencia relativa en módulos experimentales Fuente: elaboración propia, 2013.

Vol. 


\begin{tabular}{|c|c|c|c|c|c|c|c|}
\hline & Maní & Ajuga & Testigo & & Maní & Ajuga & Testigo \\
\hline $\mathrm{T}_{\text {r cielo }}$ & 25,3 & 26,0 & 40,0 & $\mathrm{~T}_{\text {r cielo }}$ & 30,7 & 31,4 & 31,5 \\
\hline $\mathrm{T}_{\mathrm{r} \text { muro sol }}$ & 29,2 & 28,5 & 33,8 & $\mathrm{~T}_{\text {r muro sol }}$ & 33,8 & 34,1 & 33,5 \\
\hline $\begin{array}{l}\mathrm{T}_{r \text { muro }} \\
\text { sombra }\end{array}$ & 28,2 & 27,5 & 32,5 & $\mathrm{~T}_{\text {r muro sombra }}$ & 32,8 & 32,8 & 32,5 \\
\hline $\mathrm{T}_{\text {r piso }}$ & 26,5 & 27,1 & 31,1 & $\mathrm{~T}_{\text {rpiso }}$ & 32,0 & 32,7 & 31,5 \\
\hline TRM & 27,8 & 27,4 & 33,5 & TRM & 32,6 & 32,8 & 32,4 \\
\hline
\end{tabular}

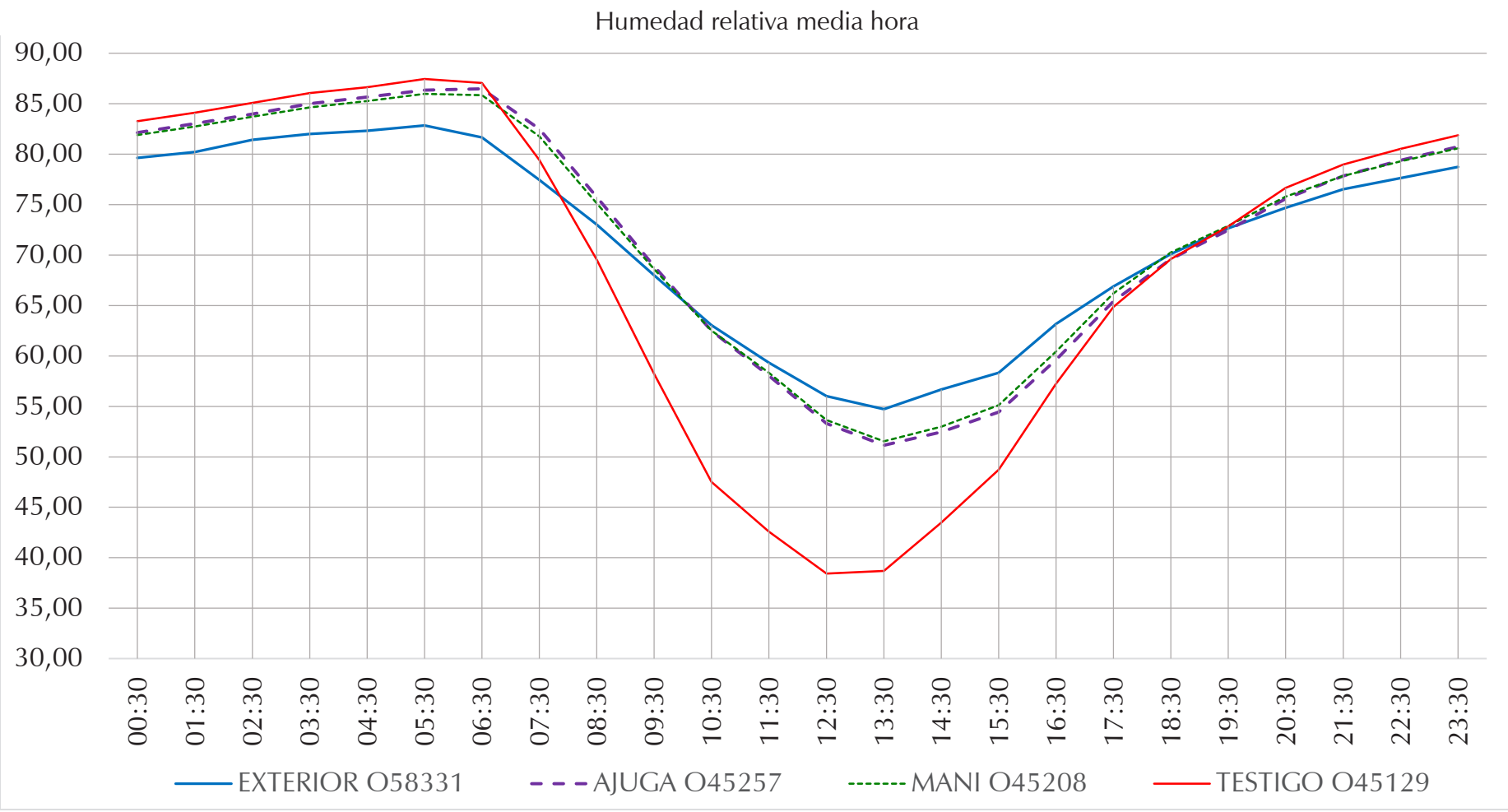

(A) Figura 11. Comparativo de la evolución del registro de la humedad relativa media horaria

Fuente: elaboración propia, 2013. que las de los módulos de experimentación. El fenómeno inverso sucede al final de la tarde. Las paredes transfieren calor al aire interior, este lo transfiere a la cubierta con convección y esta lo transfiere al entorno inmediato, siendo este proceso más rápido en la cubierta que no está protegida con techos plantados.

En los cálculos realizados se hace evidente que la temperatura de las caras internas de las paredes, y especialmente del techo, influyen directamente en el valor de la temperatura media radiante y, por tanto, en el confort térmico de los espacios interiores.

\section{Análisis de la humedad relativa}

Los valores de humedad relativa registrados muestran un comportamiento típico, donde los momentos de mayor humedad coinciden con los de menor temperatura y viceversa. La máxima oscilación diaria se presenta en el módulo testigo con un máximo de $87,5 \%$ a las 5:00 a.m. y un mínimo de $38,5 \%$ hacia el mediodía. El valor máximo en los módulos con los techos plantados es muy similar al registrado en el testigo, en cambio se presenta una diferencia significativa en los valores mínimos, que nunca registran valores por debajo de $50 \%$ (Figura 11).
En los momentos de mayor calor, la humedad relativa en los módulos de techo plantado es menor a la exterior, lo cual es muy favorable para el logro del confort térmico, desde el punto de vista de cualquiera de los métodos de evaluación (predictivo o adaptativo).

\section{Estimación del confort térmico}

El objetivo general de este estudio es la evaluación del techo plantado, como herramienta para mejorar el confort térmico al interior de los espacios. El método de Fanger, propuesto en 1973, es uno de los más completos para estimar el confort térmico ya que incorpora en su valoración la envolvente y las variables fisiológicas, entre otras.

La ecuación de confort propuesta por Fanger es bastante compleja, por lo cual se optó por utilizar el software PMVCalc_V2, desarrollado por el Laboratorio de Ventilación y Calidad del Aire de la Universidad de Gävle. Los datos obtenidos de temperatura del aire, humedad relativa y velocidad del viento se complementaron con valores estimados de actividad metabólica [Met] y vestimenta [Clo], y los valores calculados de temperatura radiante media.

La valoración del confort se realizó para los dos momentos específicos en los cuales se calculó la 


\begin{tabular}{cc} 
Maní forrajero & Resultados \\
Operative temp. $\left({ }^{\circ} \mathrm{C}\right)$ & 28,46 \\
\hline PMV & 0,8 \\
\hline PPD & 18,5 \\
\hline
\end{tabular}

\begin{tabular}{cc} 
Ajuga & Resultados \\
\hline Operative temp. $\left({ }^{\circ} \mathbf{C}\right)$ & 28,54 \\
\hline PMV & 0,8 \\
\hline PPD & 18,5 \\
\hline
\end{tabular}

\begin{tabular}{cc} 
Testigo & Resultados \\
Operative temp. $\left({ }^{\circ} \mathrm{C}\right)$ & 36,5 \\
PMV & 4,3 \\
\hline PPD & 100 \\
\hline
\end{tabular}

(A) Tabla 3. PPD y PMV - 22/03/2013 10:30 a.m.

Fuente: elaboración propia, 2013.

TRM (22/03/2013 10:30 a.m. y 09/04/2013 5:30 p.m.). Se utilizaron valores de vestimenta $[\mathrm{Clo}]$ de 0,5 , equivalentes a ropa ligera, y de actividad [Met] de 1,0, apropiados para el cálculo del confort en viviendas en el clima de Cali. Se usaron los valores de velocidad del aire de la estación Meléndez de Cenicaña.

La Tabla 3 muestra las estimaciones del confort térmico para las 10:30 a.m. del 22 de marzo de 2013. En los módulos protegidos con maní y ajuga se alcanzan niveles aceptables de satisfacción de PPD y PMV, mientras que en el módulo testigo se estima un porcentaje total de insatisfacción.

En los módulos con techos plantados se presenta un voto medio estimado PMV de 0,8 con una sensación térmica entre ligeramente caluroso y neutro, con un porcentaje de insatisfacción de 18,5\%. En cambio, el módulo testigo presenta un PMV superior a 3, por fuera de todos los rangos aceptables.

Las estimaciones del confort térmico para las 5:30 p.m. del 9 de abril de 2013 se muestran en la Tabla 4. En los módulos protegidos con maní y ajuga se alcanzan niveles aceptables de satisfacción de PPD y PMV, muy similares a los estimados para el otro momento de análisis (22/03/2013).

\section{Estimación de la resistencia térmica}

Con el propósito inferir valores de resistencia térmica de los prototipos, que sirvan para alimentar programas de simulación por computadora, se realizó un cálculo de la transferencia de calor por la cubierta desde el exterior hacia el interior del módulo testigo, utilizando los registros obtenidos durante de la etapa de experimentación y los valores de resistencia térmica suministrados por los fabricantes de la teja.

\begin{tabular}{cc} 
Maní forrajero & Resultados \\
\hline Operative temp. $\left({ }^{\circ} \mathbf{C}\right)$ & 29,45 \\
\hline PMV & 0,7 \\
\hline PPD & 15,3 \\
\hline & \\
\hline Ajuga & Resultados \\
\hline Operative temp. $\left({ }^{\circ} \mathbf{C}\right)$ & 29,86 \\
\hline PMV & 0,9 \\
\hline PPD & 22,1 \\
\hline & \\
\hline Testigo & Resultados \\
\hline Operative temp. $\left({ }^{\circ} \mathbf{C}\right)$ & 28,97 \\
PMV & 0,4 \\
\hline PPD & $\mathbf{8 , 3}$ \\
\hline
\end{tabular}

(A) Tabla 4. PPD y PMV - 09/04/2013 5:30 p.m. Fuente: elaboración propia, 2013.

Se hizo un cálculo para las 10:30 a.m. del 22/03/2013 para verificar la similitud con los valores registrados de manera experimental. Para la cubierta en fibrocemento se obtuvo un valor $U$ de $2.899 \mathrm{~W} / \mathrm{M}^{2}{ }^{\circ} \mathrm{C}$ con una $\mathrm{T}_{\mathrm{r}}$ de $39,38{ }^{\circ} \mathrm{C}$ muy similar al registro de $40^{\circ} \mathrm{C}$ tomado en sitio con el termómetro infrarrojo.

Utilizando las mismas ecuaciones, pero conociendo el valor de temperatura radiante, se calculó el valor de U para el sistema de techo plantado propuesto (maní o ajuga) obteniendo un valor de $1.549 \mathrm{~W} / \mathrm{M} 2{ }^{\circ} \mathrm{C}$ que representa un valor de $\mathrm{R}=0,645 \mathrm{M}^{2}{ }^{\circ} \mathrm{C} / \mathrm{W}$.

El valor de resistencia térmica obtenido mediante este proceso servirá para la realización de simulaciones del comportamiento térmico del prototipo.

\section{Discusión}

El desempeño térmico esperado del sistema supone una interacción de los diferentes componentes, que produce en conjunto una considerable reducción en la transferencia de calor desde el exterior hacia el interior de los módulos experimentales. El follaje produce reflexión de la radiación de onda larga, las plantas utilizan la energía de los alrededores para evaporar agua y realizar fotosíntesis, reduciendo la temperatura del aire circundante mediante un proceso de evapotranspiración.

La sombra producida por la vegetación evita el calentamiento del sustrato y, por tanto, retarda su pérdida de humedad por evaporación, garantizando que su temperatura esté por debajo de la temperatura del aire durante los periodos calurosos. De esta manera, la capa de sustrato conserva sus propiedades como aislante térmico y reduce la transferencia de calor hacia las bandejas de aluminio. Al sobreponer las bandejas de aluminio plantadas sobre las ondulaciones de la teja

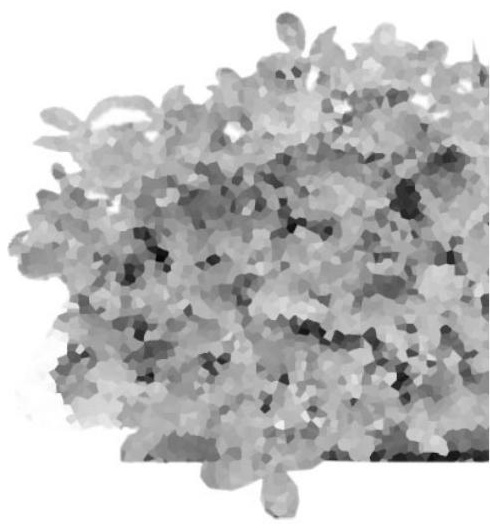


de fibrocemento se genera una serie de conductos de aire que permiten el enfriamiento por convección y reducen la transferencia de calor desde el exterior hacia el interior de los módulos. Adicionalmente, y debido a su baja emisividad $(0,05)$, un muy bajo porcentaje del calor de la bandeja de aluminio es transferido a la teja de fibrocemento por radiación.

Mediante la combinación de todas estas variables, la teja de fibrocemento recibe un porcentaje muy bajo del total de la radiación solar incidente sobre la cubierta, garantizando una reducción en la ganancia térmica al interior de los módulos experimentales.

Durante las nueve semanas de monitoreo, los módulos experimentales protegidos con vegetación registraron una menor temperatura interior; sin embargo, el módulo protegido con maní forrajero se hizo menos eficiente con el paso del tiempo, debido a la pérdida de follaje.

Al final de las tardes el módulo testigo alcanzó unos mayores niveles de confort comparativamente con los módulos protegidos con techos plantados. Este fenómeno se atribuye a la resistencia que presenta el techo a la transferencia de calor desde el interior hacia el exterior durante las horas de la tarde cuando comienza a bajar la temperatura ambiente. Se presenta un voto medio estimado PMV de 0,4, muy cercano a la sensación térmica neutra, con un porcentaje de insatisfacción muy bajo (8,3\%).

La eficiencia relativa como sistema de climatización pasiva de los prototipos de techo plantado se determina a partir de la diferencia de temperatura media entre la temperatura de referencia, la temperatura del aire al interior del módulo testigo y la del aire al interior de los módulos experimentales. Al considerar que los tres módulos (testigo + 2 experimentales) poseen los mismos coeficientes de transferencia de calor a través de sus paredes y piso, la única diferencia entre ellos es la configuración del techo y, por tanto, las diferencias de temperatura entre los módulos es causada únicamente por el tipo de cubierta implantada en cada módulo experimental.

Así, la eficiencia relativa es proporcional a la caída de temperatura interior de los módulos experimentales respecto a la del módulo testigo, y evalúa de manera comparativa la posible eficiencia de un sistema como mecanismo de climatización pasiva, estimando el porcentaje de horas en las que se lograría evitar el uso de sistemas de enfriamiento dependientes de las energías convencionales

Los valores de eficiencia energética obtenidos durante la experimentación permitieron determinar que este parámetro está directamente relacionado con el contenido de humedad del sustrato. Esto se puede inferir porque la eficiencia bajó considerablemente durante el periodo seco y fue aumentando con la aparición de las lluvias y, por consiguiente, con la recuperación del follaje de las plantas, especialmente en los prototipos cubiertos con ajuga, como lo muestra la Figura 10.

\section{Conclusiones}

El análisis comparativo permitió determinar que los sistemas de techo plantado propuestos logran una muy buena reducción de la temperatura interior durante los momentos más calientes del día y que, adicionalmente, evitan la excesiva pérdida de temperatura durante la noche, al evitar el enfriamiento evaporativo hacia la bóveda celeste por la cubierta. Los resultados obtenidos mostraron que el prototipo con ajuga presentó un mejor comportamiento durante las últimas semanas, reduciendo la temperatura interior hasta en un $18 \%$ en comparación con el módulo testigo. Por otra parte, el maní forrajero mostró un mejor comportamiento durante las primeras semanas cuando su follaje cubría la totalidad de la capa de sustrato, Ilegando a reducir la temperatura interior en un $17,4 \%$ en comparación con el módulo testigo.

En las dos primeras semanas, la vegetación de los prototipos presentaba un muy buen índice foliar, producto de unas óptimas condiciones de riego. La escasa precipitación durante las semanas 3 y 4 afectó negativamente a la vegetación, haciendo que perdieran sus hojas y se secaran las capas de sustrato, registrándose el desempeño más bajo en los dos prototipos, que llegó a porcentajes de reducción del 14,0\% para la ajuga y $13,1 \%$ para el maní forrajero. El aumento en la precipitación desde la semana 6 favoreció la recuperación de las plantas y del contenido de humedad de los sustratos, mejorando el desempeño térmico de los techos plantados.

Los datos obtenidos durante la experimentación, y el análisis de los mismos, demuestran que en regiones cálidas subhúmedas, los sistemas de protección solar de las cubiertas con vegetación son sistemas de enfriamiento pasivo eficiente, que mejoran el comportamiento higrotérmico al interior de las edificaciones, reduciendo la transferencia de calor a través de la envolvente. Al no requerir energía eléctrica para su funcionamiento, se constituyen en una alternativa eficiente, económica y ambientalmente apropiada para refrigerar las viviendas en las condiciones climáticas de Cali.

El análisis del comportamiento térmico en cada uno de los módulos experimentales permitió establecer que la mayor eficiencia de los prototipos, como sistemas de enfriamiento pasivo, se presenta cuando los sustratos tienen un alto contenido de humedad y actúan como aislante térmico. La vegetación participa activamente en el balance térmico del sistema como mecanismo de reflexión de la radiación solar y como elemento de sombreado del sustrato, evitando la pérdida de humedad por evaporación. 
La selección de la vegetación que se debe utilizar en un sistema de techo plantado para Cali debe considerar una alta resistencia a las condiciones climáticas locales, para garantizar que las plantas sirvan como elemento de protección del sustrato y así asegurar el adecuado desempeño como sistema de enfriamiento pasivo.

El cálculo de la temperatura media radiante al interior de los módulos experimentales permitió corroborar la influencia que ejerce la resistencia térmica de la cubierta en la temperatura de los espacios interiores y, por consiguiente, en el confort humano. Las valoraciones realizadas con el índice de Fanger permitieron demostrar que los dispositivos de techo plantado propuestos pueden ser una solución efectiva y pertinente para mejorar el confort en las viviendas de interés social en Cali.

Por último, se pudo inferir un valor de resistencia térmica $[R]$ para el sistema propuesto, lo cual facilitará la realización de simulaciones computarizadas de desempeño térmico y eficiencia energética.

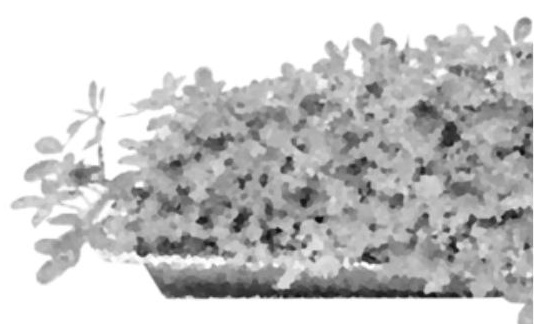

\section{Referencias}

Akbari, H., Menon, S. y Rosenfeld, A. (2009). Global cooling: increasing world-wide urban albedos to offset CO 2. Climatic Change, 94 (3), 275-286. doi: https://doi.org/10.1007/ s10584-008-9515-9

Alexandri, E. y Jones, P. (2008). Temperature decreases in an urban canyon due to green walls ygreen roofs in diverse climates. Building and Environment, 43 (4), 480-493. doi: https:// doi.org/10.1016/j.buildenv.2006.10.055

Ayata, T., Tabares-Velasco, P. C. y Srebric, J. (2011). An investigation of sensible heat fluxes at a green roof in a laboratory setup. Building and Environment, 46 (9), 1851-1861. doi: https://doi.org/10.1016/j. buildenv.2011.03.006

Bansal, N., Hauser, G. y Minke, G. (1994). Passive building design, a Handbook of Natural Climatic Control. Elsevier Science B. V.

Bell, H. y Spolek, G. (2009). Measured energy performance of greenroofs. Paper presented at the Seventh Annual International Greening Rooftops for Sustainable Communities Conference, Atlanta, GA.

Fajardo Velazco, L. F. (2005). Desempeño costo-beneficio de dos sistemas pasivos de climatizacion en cubiertas para climas cálidos-subhúmedos (Tesis de maestría). Universidad de Colima, México. Recuperado de http://digeset.ucol.mx/tesis_posgrado/ resumen.php?ID=1566

Feng, C., Meng, Q. y Zhang, Y. (2010). Theoretical and experimental analysis of the energy balance of extensive green roofs. Energy and buildings, 42 (6), 959-965. doi: http://dx.doi. org/10.1016/j.enbuild.2009.12.014

Gamboa, J. D., Rosillo, M. E., Herrera, C. A., López Bernal, O. e Iglesias García, V. (2011). Confort ambiental en vivienda de interés social en Cali. Cali: Programa Editorial Universidad del Valle.

Gameros González, G. (2007). Agua encapsulada como amortiguador térmico sobre losas de concreto (Tesis de maestría). Universidad de Colima, México. Recuperado de http:// digeset.ucol.mx/tesis_posgrado/resumen. php?ID=1679

González García, S. I. (2011). Estudio experimental del comportamiento térmico de sistemas pasivos de enfriamiento cálido-húmedo (Tesis de maestría). Universidad Internacional de Andalucía, España. Recuperado de http://dspace. unia.es/bitstream/handle/10334/778/0152 Gonzalez.pdf?sequence $=3$

Haro Carbajal, E. T. (2009). Comportamiento de dos tipos de cubiertas vegetales, como dispositivos de climatizacion para climas cálido sub-húmedos. Universidad de Colima, México. Recuperado de http://digeset.ucol. mx/tesis_posgrado/resumen.php?ID $=1736$
Hodo-Abalo, S., Banna, M. y Zeghmati, B. (2012). Performance analysis of a planted roof as a passive cooling technique in hothumid tropics. Renewable Energy, 39 (1) 140-148. doi: https://doi.org/10.1016/j. renene.2011.07.029

Humphreys, M. A. y Nicol, J. F. (2002). The validity of ISO-PMV for predicting comfort votes in every-day thermal environments. Energy and buildings, 34 (6), 667-684. doi: https://doi.org/10.1016/ S0378-7788(02)00018-X

Jim, C. Y. y He, H. (2010). Coupling heat flux dynamics with meteorological conditions in the green roof ecosystem. Ecological Engineering, 36 (8), 1052-1063. doi: http:// dx.doi.org/10.1016/j.ecoleng.2010.04.018

Kotsiris, G., Androutsopoulos, A., Polychroni, E. y Nektarios, P. A. (2012). Dynamic $\cup$-value estimation and energy simulation for green roofs. Energy and buildings, 45, 240-249. doi: http://dx.doi.org/10.1016/j. enbuild.2011.11.005

Lazzarin, R. M., Castellotti, F. y Busato, F (2005). Experimental measurements and numerical modelling of a green roof. Energy and Buildings, 37 (12), 1260-1267. doi: 10.1016/j.enbuild.2005.02.001

Mentens, J., Raes, D. y Hermy, M. (2006). Green roofs as a tool for solving the rainwater runoff problem in the urbanized 21st century? Landscape and urban planning, 77 (3), 217-226. doi: https://doi.org/10.1016/j. landurbplan.2005.02.010

Morales, G. C. B. y Cruz, E. M. G. (2003). Confort térmico en el trópico húmedo: experiencias de campo en viviendas naturalmente ventiladas. Ambiente construido 3 (2), 47-55. doi: http://www.seer.ufrgs. br/index.php/ambienteconstruido/article/ view/3450/1869

Niachou, A., Papakonstantinou, K., Santamouris, M. Tsangrassoulis, A. y Mihalakakou, G. (2001). Analysis of the green roof thermal properties and investigation of its energy performance. Energy and buildings, 33 (7), 719-729. doi: https://doi.org/10.1016/ S0378-7788(01)00062-7

Oberndorfer, E., Lundholm, J., Bass, B., Coffman, R. R., Doshi, H., Dunnett, N. et al. (2007). Green roofs as urban ecosystems: ecological structures, functions, and services. Bioscience, 57 (10), 823-833. doi: https://doi.org/10.1641/B571005

Olgyay, V. (1968). Clima y arquitectura en Colombia. Cali: Universidad del Valle.

Onmura, S., Matsumoto, M. y Hokoi, S. (2001). Study on evaporative cooling effect of roof lawn gardens. Energy and buildings, 33 (7), 653-666. doi: http://dx.doi.org/10.1016/ S0378-7788(00)00134-1
Osuna Motta, I. (2013). Prototipo de techo plantado como dispositivo de climatización pasiva en Cali (Trabajo de grado). Universidad del valle, Cali, Colombia.

Parizotto, S. y Lamberts, R. (2011). Investigation of green roof thermal performance in temperate climate: A case study of an experimental building in Florianópolis city, Southern Brazil. Energy and buildings, 43 (7), 1712-1722. doi: https:// doi.org/10.1016/j.enbuild.2011.03.014

Sánchez G. L. H. (1993). Evaluación de un techo estanque como sistema de enfriamiento pasivo en un clima cálido sub-húmedo (Tesis de maestría). Universidad de Colima, México. Recuperado de http://digeset.ucol.mx/tesis posgrado/resumen.php?ID =154

Santamouris, M. y Asimakopoulos, D. (1996). Passive cooling of buildings. London: Earthscan/James \& James.

Santana, L. M., Escobar, L. A. y Capote, P. A. (2011). Influencia de los cambios de ocupación del suelo de Cali (Colombia), entre 1984 y 2003. en la temperatura de superficie. Ingeniería y Competitividad, 13(1). Recuperado de http:// www.redalyc.org/html/2913/291323660011/

Susca, T., Gaffin, S. y Dell'Osso, G. (2011). Positive effects of vegetation: Urban heat island and green roofs. Environmental Pollution, 159 (8), 2119-2126. doi: https://doi.org/10.1016/j. envpol.2011.03.007

Tabares-Velasco, P. C. y Srebric, J. (2011). Experimental quantification of heat and mass transfer process through vegetated roof samples in a new laboratory setup. International Journal of Heat and Mass Transfer, 54 (25), 5149-5162. doi: https://doi.org/10.1016/j. ijheatmasstransfer.2011.08.034

Theodosiou, T. G. (2003). Summer period analysis of the performance of a planted roof as a passive cooling technique. Energy and buildings, 35 (9), 909-917. doi: https://doi. org/10.1016/S0378-7788(03)00023-9

Tsang, S. y Jim, C. (2011). Theoretical evaluation of thermal and energy performance of tropical green roofs. Energy, 36 (5), 35903598. doi: https://doi.org/10.1016/j.energy.2011.03.072

UCLA, E. d. t. (2013). Climate consultant software (Version 5.4). www.energy-designtools.aud.ucla.edu.

Wong, N. H., Chen, Y., Ong, C. L. y Sia, A. (2003). Investigation of thermal benefits of rooftop garden in the tropical environment. Building and Environment, 38 (2), 261-270. doi: http:// dx.doi.org/10.1016/S0360-1323(02)00066-5 
La postulación de un artículo a la Revista de Arquitectura indica que- el o los autores certifican que conocen y aceptan la política editorial, para lo cual firmarán en original y remitirán el formato RevArq FP00 Carta de originalidad.

La Revista de Arquitectura maneja una política de Autoarchivo VERDE, según las directrices de SHERPA/RoMEO, por lo cual el autor puede:

- Pre-print del autor: Archivar la versión pre-print (la versión previa a la revisión por pares)

- Post-print del autor: Archivar la versión post-print (la versión final posterior a la revisión por pares)

- Versión de editor/PDF: Archivar la versión del editor - PDF/HTML/XLM en la maqueta de la Revista de Arquitectura.

El Autoarchivo se debe hacer respetando la licencia de acceso abierto, la integridad y la imagen de la Revista de Arquitectura, también se recomienda incluir la referencia, el vínculo electrónico y el DOI.

El autor o los autores son los titulares del Copyright (c) del texto publicado y la Editorial de la Revista de Arquitectura solicita la firma de una autorización de reproducción del artículo (RevArq FP03 Autorización reproducción), la cual se acoge a la licencia CC, donde se expresa el derecho de primera publicación de la obra.

La Revista de Arquitectura se guía por las normas internacionales sobre propiedad intelectual y derechos de autor, y de manera particular el artículo 58 de la Constitución Política de Colombia, la Ley 23 de 1982 y el Acuerdo 172 del 30 de septiembre de 2010 (Reglamento de propiedad intelectual de la Universidad Católica de Colombia).

Para efectos de autoría y coautoría de artículos se diferencian dos tipos: "obra en colaboración" y "obra colectiva". La primera es aquella cuya autoría corresponde a todos los participantes al ser fruto de su trabajo conjunto. En este caso, quien actúa como responsable y persona de contacto debe asegurar que quienes firman como autores han revisado y aprobado la versión final, y dan consentimiento para su divulgación. La obra colectiva es aquella en la que, aunque participan diversos colaboradores, hay un autor que toma la iniciativa, la coordinación y realización de dicha obra. En estos casos, la autoría corresponderá a dicha persona (salvo pacto en contrario) y será suficiente únicamente con su autorización de divulgación.

El número de autores por artículo debe estar justificado por el tema, la complejidad y la extensión, y no deberá ser superior a la media de la disciplina, por lo cual se recomienda que no sea mayor de cinco. El orden en que se enuncien corresponderá a los aportes de cada uno a la construcción del texto, se debe evitar la autoría ficticia o regalada. Si se incluyen más personas que trabajaron en la investigación se sugiere que sea en calidad de colaboradores o como parte de los agradecimientos. La Revista de Arquitectura respetará el número y el orden en que figuren en el original remitido. Si los autores consideran necesario, al final del artículo pueden incluir una breve descripción de los aportes individuales de cada uno de firmantes.

La comunicación se establece con uno de los autores, quien a su vez será el responsable de informar a los demás autores de las notificaciones emitidas por la Revista de Arquitectura.

En virtud de mantener el equilibro de las secciones y las mismas oportunidades para todos los participantes, un mismo autor puede postular dos o más artículos de manera simultánea; si la decisión editorial es favorable y los artículos son aceptados, su publicación se realizará en números diferentes.

\section{(A) Acceso abierto}

La Revista de Arquitectura, en su misión de divulgar la investigación y apoyar el conocimiento y la discusión en los campos de interés, proporciona acceso abierto, inmediato e irrestricto a su contenido de manera gratuita mediante la distribución de ejemplares impresos y digitales. Los interesados pueden leer, descargar, guardar, copiar y distribuir, imprimir, usar, buscar o referenciar el texto completo o parcial de los artículos o la totalidad de la Revista de Arquitectura.

\section{(1) (3)}

Esta revista se acoge a la licencia Creative Commons (CC BYNC de Atribución - No comercial 4.0 Internacional): "Esta licencia permite a otros entremezclar, ajustar y construir a partir de su obra con fines no comerciales, y aunque en sus nuevas creaciones deban reconocerle su autoría y no puedan ser utilizadas de manera comercial, no tienen que estar bajo una licencia con los mismos términos".

La Revista de Arquitectura es divulgada en centros y grupos de investigación, en bibliotecas y universidades, y en las principales facultades de Arquitectura, mediante acceso abierto a la versión digital y suscripción anual al ejemplar impreso o por medio de canje, este último se formaliza mediante el formato RevArq FP20 Canjes.

Para aumentar su visibilidad y el impacto de los artículos, se envían a bases de datos y sistemas de indexación y resumen (SIR) y, asimismo, pueden ser consultados y descargados en la página web de la revista.

La Revista de Arquitectura no maneja cobros, tarifas o tasas de publicación de artículo (Article Processing Charge-APC), o por el sometimiento de textos a la publicación.

\section{(1) Ética y buenas prácticas}

La Revista de Arquitectura se compromete a cumplir y respetar las normas éticas en todas las etapas del proceso de publicación. Los autores de los artículos publicados darán cumplimiento a los principios éticos contenidos en las diferentes declaraciones y legislaciones sobre propiedad intelectual y derechos de autor específicos del país donde se realizó la investigación. En consecuencia, los autores de los artículos postulados y aceptados para publicar, que presentan resultados de investigación, deben firmar la declaración de originalidad (formato RevArq FP00 Carta de originalidad).

La Revista de Arquitectura reconoce y adopta los principios de transparencia y buenas prácticas descritos por COPE, "Principles of Transparency and Best Practice in Scholarly Publishing" (2015).

El equipo editorial tiene la obligación de guardar la confidencialidad acerca de los artículos recibidos, y abstenerse de usar en sus propias investigaciones datos, argumentos o interpretaciones hasta tanto el artículo no sea publicado. También debe ser imparcial y gestionar los artículos de manera adecuada y en los plazos establecidos. La selección de revisores se hará con objetividad y estos deberán responder a la temática del artículo.

El editor, los autores y los revisores deben seguir las normas éticas internacionales definidas por el Committee on Publication Ethics (COPE), con el fin de evitar casos de:

- Fabricación, falsificación u omisión de datos.

- Plagio y autoplagio.

- Publicación redundante, duplicada o fragmentada.

- Omisión de referencias a las fuentes consultadas.

- Utilización de contenidos sin permiso o sin justificación.

- Apropiación individual de autoría colectiva.

- Cambios de autoría.

- Conflicto de interés (CDI) no revelado o declarado.

- Otras que pudieran surgir en el proceso de investigación y publicación. La fabricación de resultados se genera al mostrar datos inventados por los autores; la falsificación resulta cuando los datos son manipulados y cambiados a capricho de los autores; la omisión se origina cuando los autores ocultan deliberadamente un hecho o dato. El plagio se da cuando un autor presenta como ideas propias datos creados por otros. Los casos de plagio son los siguientes: copia directa de un texto sin entrecomillar o citar la fuente, modificación de algunas palabras del texto, paráfrasis y falta de agradecimientos; el autoplagio se da cuando el mismo autor reutiliza material propio que ya fue publicado, pero sin indicar la referencia al trabajo anterior. La revista se apoya en herramientas digitales que detectan cualquiera de estos casos en los artículos postulados, y es labor de los editores y revisores velar por la originalidad y fidelidad en la citación. La publicación redundante o duplicada se refiere a la copia total, parcial o alterada de un trabajo ya publicado por el mismo autor

En caso de sospechar de alguna mala conducta se recomienda seguir los diagramas de flujo elaborados por COPE (2008), con el fin de determinar las acciones correspondientes.

La Revista de Arquitectura se reserva el derecho de retractación de publicación de aquellos artículos que, posterior a su publicación, se demuestre que presentan errores de buena fe, o cometieron fraudes o malas prácticas científicas. Esta decisión se apoyará en "Retraction Guidelines" (COPE, 2009). Si el error es menor, este se podrá rectificar mediante una nota editorial de corrección o una fe de erratas. Los autores también tienen la posibilidad de solicitar la retractación de publicación cuando descubran que su trabajo presenta errores graves. En todos los casos se conservará la versión electrónica y se harán las advertencias de forma clara e inequívoca.

\section{(A) Privacidad y manejo de la información.} Habeas Data

Para dar cumplimiento a lo previsto en el artículo 10 del Decreto 1377 de 2013, reglamentario de la Ley 1581 de 2012, y según el Acuerdo 002 del 4 de septiembre de 2013 de la Universidad Católica de Colombia, "por el cual se aprueba el manual de políticas de tratamiento de datos personales":

La Universidad Católica de Colombia, considerada como responsable o encargada del tratamiento de datos personales, manifiesta que los datos personales de los autores, integrantes de los comités y pares revisores, se encuentran incluidos en nuestras bases de datos; por lo anterior, y en cumplimiento de las disposiciones legales vigentes, la Universidad solicitará siempre su autorización, para que en desarrollo de sus funciones propias como Institución de Educación Superior, en especial las relacionadas con la docencia, la extensión y la investigación, la Universidad Católica de Colombia pueda recolectar, recaudar, almacenar, usar, circular, suprimir, procesar, intercambiar, compilar, dar tratamiento, actualizar, transmitir o transferir a terceros países y disponer de los datos que le han suministrado y que han sido incorporados en las bases de datos de todo tipo que reposan en la Universidad.

La Universidad Católica de Colombia queda autorizada, de manera expresa e inequívoca, en los términos señalados por el Decreto 1377 de 2013, para mantener y manejar la información de nuestros colaboradores (autores, integrantes de los diferentes comités y pares revisores); así mismo, los colaboradores podrán ejercer sus derechos a conocer, actualizar, rectificar y suprimir sus datos personales, para lo cual se han dispuesto las siguientes cuentas de correo electrónico: 
La Revista de Arquitectura recibe artículos de manera permanente. Los artículos se procesan a medida que se postulan, dependiendo el flujo editorial de cada sección.

El idioma principal es el español, y como opcionales están definidos el inglés, el portugués y el francés; los textos pueden ser escritos y presentados en cualquiera de estos.

Los artículos postulados deben corresponder a las categorías universalmente aceptadas como producto de investigación, ser originales e inéditos y sus contenidos responder a criterios de precisión, claridad y brevedad.

Como punto de referencia se pueden tomar las tipologías y definiciones del Índice Bibliográfico Nacional, Publindex (2010) que se describen la continuación:

1. Artículo de revisión: documento resultado de una investigación terminada donde se analizan, sistematizan e integran los resultados de investigaciones publicadas o no publicadas, sobre un campo en ciencia o tecnología, con el fin de dar cuenta de los avances y las tendencias de desarrollo. Se caracteriza por presentar una cuidadosa revisión bibliográfica de por lo menos 50 referencias.
2. Artículo de investigación científica y tecnológica: documento que presenta, de manera detallada, los resultados originales de proyectos terminados de investigación. La estructura generalmente utilizada contiene cuatro apartes importantes: introducción, metodología, resultados y conclusiones.

3. Artículo de reflexión: documento que presenta resultados de investigación terminada desde una perspectiva analítica, interpretativa o crítica del autor, sobre un tema específico, recurriendo a fuentes originales.

En todos los casos se debe presentar la información suficiente para que cualquier investigador pueda reproducir la investigación y confirmar o refutar las interpretaciones defendidas.

También se pueden presentar otro tipo de documentos diferentes a los anteriormente descritos, como pueden ser: artículo corto, reporte de caso, revisión de tema, documento resultado de la revisión crítica de la literatura sobre un tema en particular, cartas al editor, traducción, documento de reflexión no derivado de investigación, reseña bibliográfica, así como proyectos de arquitectura o urbanismo, entre otros

\section{(A) Instrucciones para postular artículos}

Postular el artículo en la página web de la Revista de Arquitectura y adjuntar comunicación escrita dirigida al editor RevArq_FP00 Carta de originalidad (debidamente firmada por todos los autores en original); de igual manera, se debe diligenciar el formato de hoja de vida RevArq FP01 Hoja de Vida (una por cada autor).

En la comunicación escrita el autor expresa que conoce y acepta la política editorial de la Revista de Arquitectura, que el artículo no está postulado para publicación simultáneamente en otras revistas u órganos editoriales y que no existe conflicto de intereses (ver modelo RevArq FP06 CDI) y que, de ser aceptado, concederá permiso de primera publicación, no exclusiva a nombre de la Universidad Católica de Colombia como editora de la revista.

Los artículos deben tener en cuenta las siguientes recomendaciones:

- En la primera página del documento se debe incluir:

Título: no exceder 15 palabras.

Subtítulo: opcional, complementa el título o indica las principales subdivisiones del texto.

Nombre del autor o autores: nombres y apellidos completos o según modelo de citación adoptado por el autor para la normalización de los nombres del investigador. Como nota al pie (máximo 150 palabras): formación académica, experiencia profesional e investigativa, vinculación laboral, código ORCID, premios o reconocimientos, publicaciones representativas e información de contacto, correo electrónico.

Filiación institucional: debajo del nombre se debe declarar la institución en la cual se desarrolló el producto, de la cual recibió apoyo o aquella que respalda el trabajo investigativo.

Resumen: debe ser analítico, se redacta en un solo párrafo, da cuenta del tema, el objetivo, la metodología, los resultados y las conclusiones; no debe exceder las 150 palabras.

Palabras clave: cinco palabras o grupo de palabras, ordenadas alfabéticamente y que no se encuentren en el título o subtítulo; estas sirven para clasificar temáticamente al artículo. Se recomienda emplear principalmente palabras definidas en el tesauro de la Unesco (http:// databases.unesco.org/thessp/), en el tesauro de Arte \& Arquitectura (C) (www.aatespanol.cl), o Vitruvio (http://vocabularyserver.com/vitruvio/)

También se recomienda incluir título, resumen y palabras clave en segundo idioma.

- La segunda página y siguientes deben tener en cuenta:

El cuerpo del artículo generalmente se divide en: Introducción, Metodología, Resultados y Discusión de resultados; posteriormente se presentan las Conclusiones, y luego las Referencias bibliográficas y los Anexos (método IMRYD). Las tablas y figuras se deben incorporar en el texto.

Descripción del proyecto de investigación: en la introducción se debe describir el tipo de artículo y brevemente el marco investigativo del cual es resultado y diligenciar el formato (RevArq FP02 Info Proyectos de Investigación).

TEXTO: todas las páginas deben venir numeradas y con el título de artículo en la parte superior de la página. Márgenes de $3 \mathrm{~cm}$ por todos los lados, interlineado doble, fuente Arial o Times New Roman de 12 puntos, texto justificado (Ver plantilla para presentación de artículos). La extensión de los artículos debe ser de alrededor de 5.000 palabras ( \pm 20 páginas, incluyendo gráficos, tablas, referencias, etc.); como mínimo 3.500 y máximo 8.000 palabras. Se debe seguir el estilo vigente y recomendado en el Manual para Publicación de la American Psychological Association (APA). (Para mayor información véase http://www.apastyle.org/)
Citas y notas al pie: las notas aclaratorias o notas al pie no deben exceder cinco líneas o 40 palabras, de lo contrario estas deben ser incorporadas al texto general. Las citas pueden ser:

Corta: (con menos de 40 palabras) se incorporan al texto y pueden ser: textuales (se encierran entre dobles comillas), parafraseo o resumen (se escriben en palabras del autor dentro del texto).

Cita textual extensa: (mayor de 40 palabras) debe ser dispuesta en un renglón y un bloque independiente con sangrías y omitiendo las comillas, no olvidar en ningún caso la referencia del autor (Apellido, año, página).

Referencias: como modelo para la construcción de referencias se emplea el estilo recomendado en el Manual para Publicación de la American Psychological Association (APA) (http://www.apastyle.org/).

Siglas: en caso de emplear siglas en el texto, las figuras o las tablas, se debe proporcionar la equivalencia completa la primera vez que se empleen y encerrarlas entre paréntesis. En el caso de citar personajes reconocidos se deben colocar nombres o apellidos completos, nunca emplear abreviaturas.

Figuras y tablas: las figuras (gráficos, diagramas, ilustraciones, planos, mapas o fotografías) y las tablas deben ir numeradas y contener título o leyenda explicativa relacionada con el tema del artículo, que no exceda las 15 palabras (Figura 1. xxxxx, Tabla 1. xxxx, etc.) y la procedencia (fuente: autor o fuente, año, página). Estas se deben referenciar en el texto de forma directa o entre paréntesis; se recomienda hacerlo con referencias cruzadas.

También se deben entregar en medio digital, independiente del texto, en formatos editables o abiertos. La marcación de los archivos debe corresponder a la incluida en el texto. Según la extensión del artículo se deben incluir de 5 a 10 gráficos. Ver guía para la búsqueda de imágenes de dominio público o bajo licencias Creative Commons (CC).

El autor es el responsable de adquirir los derechos o las autorizaciones de reproducción a que haya lugar para imágenes o gráficos tomados de otras fuentes, así como de entrevistas o material generado por colaboradores diferentes a los autores; de igual manera, se debe garantizar la protección de datos e identidades para los casos que sea necesario.

FotografíA: pueden ser entregadas en original para ser digitalizadas, de lo contrario se deben digitalizar con una resolución igual o superior a 300 dpi para imágenes a color y 600 para escala de grises. Los formatos de las imágenes pueden ser TIFF, PSD o JPG, y deben cumplir con las características expresadas en el punto anterior (figuras).

Planimetría: se debe entregar la planimetría original en medio digital, en lo posible en formato CAD, y sus respectivos archivos de plumas o en PDF; de no ser posible, se deben hacer impresiones en tamaño carta con las referencias de los espacios mediante numeración y lista adjunta. Deben tener escala gráfica, escala numérica, norte, coordenadas y localización. En lo posible, no deben contener textos, achurados o tramas.

Para más detalles, consultar el documento RevArq Parámetros para Autores Descripción en el portal web de la Revista de Arquitectura

\section{Beneficios}

Como reconocimiento a los autores, se les hará envío postal de dos ejemplares de la edición impresa sin ningún costo y entregada en la dirección consignada en el formato de hoja de vida (RevArq FP01); adicionalmente, se enviará el vínculo para la descarga de la versión digital.

También se enviará una constancia informativa en la que se relaciona la publicación del artículo y, de manera opcional, se pueden detallar las fechas del proceso editorial y el arbitraje realizado. 
La selección de revisores se realiza de acuerdo con los siguientes criterios:

- Afinidad temática.

- Formación académica.

- Experiencia investigativa y profesional.

- Producción editorial en revistas similares o en libros resultado de investigación.

El proceso de arbitraje se basa en los principios de equidad e imparcialidad, y en los criterios de calidad y pertinencia.

El desarrollo de la revisión se realiza según el formato (RevArq FP10 Evaluación de artículos) y las observaciones que el revisor considere necesarias en el cuerpo del artículo. En cualquiera de los conceptos que emita el revisor (Aceptar, Publicable con modificaciones, Reevaluable o No publicable), y como parte de la labor formativa y de comunidad académica, el revisor hará sugerencias para mejorar el documento. El revisor podrá solicitar una nueva relectura del artículo después de los ajustes realizados por el autor.

El revisor también deberá diligenciar el formato RevArq FP01 Hoja de Vida, con el fin de certificar y soportar el proceso de revisión ante los SIR que así lo soliciten.

En el proceso de arbitraje se emplea el método doble ciego, los nombres del revisor no serán conocidos por el autor y viceversa. Con el fin de garantizar el anonimato del autor, al artículo postulado se le han podido suprimir nombres, instituciones o imágenes que puedan ser asociadas de manera directa al autor.

Aunque se procura el anonimato, una vez recibida la invitación como par revisor del artículo, el revisor debe cerciorarse de que no exista conflicto de intereses (CDI) o alguna limitante que afecte la revisión o que pueda ser vista como tal (lazos familiares, amistad o enemistad, vínculos contractuales o laborales, posiciones éticas, etc.), de presentarse esta situación se notificara al editor. (Ver modelo RevArq FP06 CDI).

Dada la confidencialidad del proceso de revisión, y considerando los derechos de autor y de propiedad intelectual que pueda haber sobre el material que se entrega, el revisor se compromete a mantener en absoluta reserva su labor, a limitar el uso de la obra entregada solo para el propósito designado y a devolver la documentación remitida una vez concluya la actividad.

El tiempo establecido para las revisiones de pares es de máximo un mes a partir de la confirmación de la recepción de la documentación. Ese plazo podrá ser modificado de mutuo acuerdo entre el editor y el revisor, siempre y cuando no afecte la periodicidad de la revista, la impresión o el tiempo para emitir una respuesta al autor. Los revisores se acogerán a "COPE Ethical Guidelines for Peer Reviewers" de COPE.

\section{Beneficios}

Como retribución a los revisores se les hará envío postal de un ejemplar de la edición impresa sin ningún costo y entregada en la dirección consignada en el formato de hoja de vida. También, si es de interés para el revisor, podrá hacer la solicitud de alguna de las publicaciones editadas y presentes en el catálogo de publicaciones de la UNIVERSIDAD CATÓLICA DE COLOMBIA, previa aprobación de la Editorial y sujeto a la disponibilidad.

Si lo desea tendrá derecho a una constancia de la colaboración en la revisión de artículos, la cual solo contendrá el periodo en el cual se realizó la actividad. También tendrá la posibilidad de aceptar o no la publicación de su nombre, nacionalidad y nivel máximo de formación en la página web de la Revista de Arquitectura en su calidad de colaborador.

\section{A) Proceso de revisión por pares}

Luego de la postulación del artículo, el editor de la Revista de Arquitectura selecciona y clasifica los artículos que cumplen con los requisitos establecidos en las directrices para los autores. El editor podrá rechazar en primera instancia artículos, sin recurrir a un proceso de revisión, si los considera de baja calidad o por presentar evidencias de faltas éticas o documentación incompleta.

Los artículos se someterán a un primer dictamen del editor, de los editores de sección y del Comité Editorial, teniendo en cuenta:

- Afinidad temática, relevancia del tema y correspondencia con las secciones definidas.

- Respaldo investigativo.

- Coherencia en el desarrollo del artículo, así como una correcta redacción y ortografía.

- Relación entre las figuras y tablas con el texto del artículo.
En esta revisión se verificará el nivel de originalidad mediante el uso de software especializado (Ithenticate o similar) y recursos digitales existentes para tal fin, también se observará la coherencia y claridad en los apartados del documento (modelo IMRYD), la calidad de las fuentes y la adecuada citación, esto quedará consignado en el formato (RevArq FP09 Revisión de artículos); esta información será cargada a la plataforma de gestión editorial y estará a disposición del autor.

En caso de que el artículo requiera ajustes preliminares, será devuelto al autor antes de ser remitido a revisores. En este caso, el autor tendrá veinte días para remitir nuevamente el texto con los ajustes solicitados.

Después de la preselección se asignan mínimo dos revisores especializados, quienes emitirán su concepto utilizando el formato (RevArq FP10 Evaluación de artículos) y las anotaciones que consideren oportunas en el texto; en esta etapa se garantizará la confidencialidad y el anonimato de autores y revisores (modalidad doble ciego)

Del proceso de revisión se emite uno de los siguientes conceptos que será reportado al autor:

- Aceptar el envío: con o sin observaciones.

- Publicable con modificaciones: se podrá sugerir la forma más adecuada para una nueva presentación, el autor puede o no aceptar las observaciones según sus argumentos. Si las acepta, cuenta con quince días para realizar los ajustes pertinentes.

- Reevaluable: cumple con algunos criterios y debe ser corregido. Es necesario hacer modificaciones puntuales y estructurales al artículo. En este caso, el revisor puede aceptar o rechazar hacer una nueva lectura del artículo luego de ajustado.

- No publicable: el autor puede volver a postular el artículo e iniciar nuevamente el proceso de arbitraje, siempre y cuando se evidencien los ajustes correspondientes.

En el caso de presentarse diferencias sustanciales y contradictorias en los conceptos sobre la recomendación del revisor, el editor remitirá el artículo a un revisor más o a un miembro del Comité Editorial quien podrá actuar como tercer árbitro, con el fin de tomar una decisión editorial sobre la publicación del artículo.

Los autores deberán considerar las observaciones de los revisores o de los editores, y cada corrección incorporada u omitida debe quedar justificada en el texto o en una comunicación adjunta. En el caso que los autores omitan las indicaciones realizadas sin una argumentación adecuada, el artículo será devuelto y no se dará por recibido hasta que no exista claridad al respecto.

El editor respetará la independencia intelectual de los autores y a estos se les brindará el derecho de réplica en caso de que los artículos hayan sido evaluados negativamente y rechazados.

Los autores, con su usuario y contraseña, podrán ingresar a la plataforma de Gestión Editorial, donde encontrarán los conceptos emitidos y la decisión sobre el artículo.

El editor y el Comité Editorial se reservan el derecho de acepta o no la publicación del material recibido. También se reservan el derecho de sugerir modificaciones de forma, ajustar las palabras clave o el resumen y de realizar la corrección de estilo. El autor conocerá la versión final del texto antes de la publicación oficial del mismo.

Cuando un artículo es aceptado para su publicación, el autor debe firmar la autorización de reproducción (RevArq FP03 Autorización reproducción). Para más información ver: Política de derechos de autor

\section{Notas aclaratorias:}

La Revista de Arquitectura publica un número limitado de artículos por volumen y busca el equilibrio entre las secciones, motivo por el cual, aunque un artículo sea aceptado o continúe en proceso de revisión, podrá quedar aplazado para ser publicado en un próximo número; en este caso, el autor estará en la posibilidad de retirar la postulación del artículo o de incluirlo en el banco de artículos del próximo número.

El editor y los editores de sección de la Revista de Arquitectura son los encargados de establecer contacto entre los autores y revisores, ya que estos procesos se realizan de manera anónima. 
A favela é um cenário: tematização e cenarização nas favelas cariocas

ن் La favela es un escenario: la tematización y escenarización en las favelas de Río

The favela as a setting: Thematization and scenarization in the favelas of Rio de Janeiro

Sergio-Moraes-Rego Fagerlande

Gestión cultural del patrimonio en Viotá, Cundinamarca

De la utopía a la distopía doméstica. La creación de la vivienda modelo norteamericana

From utopia to domestic dystopia. The creation of the American model housing

Da utopia à distopia doméstica. A criação da moradia modelo norte-americana

Carlos Santamarina-Macho

La varanda gourmet brasileña: arquitectura hedonista y distinción social

The Brazilian "varanda gourmet": Hedonistic architecture and social distinction

A varanda gourmet brasileira: arquitetura hedonista diferenciação social

Bruno Cruz-Petit, Alejandro Pérez-Duarte Fernández

Techo plantado como dispositivo de climatización pasiva en el trópico

(j) Green roofs as a passive cooling device in the tropics

Telhados verdes como dispositivo de climatização passiva no Trópico

Iván Osuna-Motta, Carlos Herrera-Cáceres, Oswaldo López-Bernal

Criterios de integración de energía solar activa en arquitectura. Potencial tecnológico y consideraciones proyectuales

Criteria for the architectural integration of active solar energy. Technological potential and design attitudes

Critérios de integração de energia solar ativa em arquitetura. Potencial tecnológico e considerações projetuais

Esteban Zalamea-León, Felipe Quesada

Prototipos flexibles. Proyecto habitacional en el barrio popular Buenos Aires (Soacha)

Flexible prototypes. Housing project in the poor neighborhood of Buenos Aires (Soacha)

Protótipos flexíveis. Projeto habitacional no bairro popular Buenos Aires (Soacha)

Mildred Paola Laiton-Suárez

La pedagogía del taller en la enseñanza de la arquitectura. Una aproximación cultural y material al caso francés (siglos XIX y XX)

La pédagogie de l'atelier dans l'enseignement de l'architecture en France aux XIXe et $\mathrm{XXe}$ siècles, une approche culturelle et matérielle

Pedagogy of the workshop in the teaching of architecture. A cultural and material approach to the French case (19th and 20th centuries)

A pedagogia do ateliê no ensino da arquitetura. Uma aproximação cultural e material ao caso francês (séculos XIX e XX)

Guy Lambert

Traductores:

Andrés Ávila-Gómez

Diana Carolina Ruiz 